UNIVERSIDADE DE SÃO PAULO

ESCOLA DE ENFERMAGEM DE RIBEIRÃO PRETO

DAYANE ROSA ALVARENGA SILVA GOMES

ESTIGMA INTERNALIZADO EM PACIENTES COM TRANSTORNO DE HUMOR

E FATORES ASSOCIADOS 


\section{ESTIGMA INTERNALIZADO EM PACIENTES COM TRANSTORNO DE HUMOR E FATORES ASSOCIADOS}

Dissertação apresentada ao Programa de Pós-Graduação em Enfermagem Psiquiátrica, da Escola de Enfermagem de Ribeirão Preto, da Universidade de São Paulo, para obtenção do título de Mestre em Ciências.

Linha de Pesquisa: Enfermagem Psiquiátrica: políticas, saberes e práticas.

Orientadora: Profa. Dra. Kelly Graziani Giacchero Vedana. 
Autorizo a reprodução e divulgação total ou parcial deste trabalho, por qualquer meio convencional ou eletrônico, para fins de estudo e pesquisa, desde que citada a fonte.

Gomes, Dayane Rosa Alvarenga Silva

Estigma internalizado em pacientes com transtorno de humor e fatores associados / Ribeirão Preto, 2018.

78 p. : il. ; $30 \mathrm{~cm}$ Preto/USP.

Dissertação de Mestrado apresentada à Escola de Enfermagem de Ribeirão

Área de concentração: Enfermagem Psiquiátrica.

Orientador: Vedana, Kelly Graziane Giacchero.

1. Esperança. 2. Transtornos de humor. 3. Adesão à medicação.

4. Estigma social. 5. Preconceito. 
Nome: GOMES, Dayane Rosa Alvarenga Silva

Título: Estigma internalizado em pacientes com transtorno de humor e fatores associados

Dissertação apresentada à Escola de Enfermagem de Ribeirão Preto da Universidade de São Paulo para obtenção do título de Mestre em Ciências, Programa de Pós-Graduação Enfermagem Psiquiátrica.

Aprovado em: / /

Banca Examinadora

Prof. Dr.

Instituição:

Julgamento:

Prof. Dr.

Instituição:

Julgamento:

Prof. Dr.

Instituição:

Julgamento: 
Para minha família, minha vida, amor, tesouro...

Minha mãe Marlene, meu esposo Alcides, meu pai Eurípedes, meus irmãos Danilo e Daniel, e meu irmão de consideração Vinícius, minhas sobrinhas Laís e Maya.

Por serem a minha inspiração, meu alicerce e minha luz, em meio às dificuldades!

\section{Para Kelly}

Por ter estado ao meu lado em todos os momentos,

Por não desistir de mim,

Por todo o respeito, cumplicidade e trabalho. 


\section{AGRADECIMENTOS}

A Deus, por ser minha fonte inesgotável de inspiração, meu TUDO, por toda as oportunidades, por todas as pedras no caminho e por toda força para removê-las.

À minha mãe, por ser meu alicerce, minha guerreira, meu exemplo de mulher, minha amiga, a melhor parte de mim.

Ao meu esposo, que esteve ao meu lado em todos os momentos de crises e desespero e sempre me apoiou e mostrou que seria possível. Sem você eu não iria conseguir!

À minha orientadora, Prof ${ }^{a}$ Dra. Kelly Graziani, Giacchero Vedana, por todo o apoio, ensinamentos, compreensão, companheirismo e construção. Por estar ao meu lado desde a graduação e me mostrar que é possível orientar de maneira assertiva e carinhosa. Gratidão por todo o aprendizado e respeito.

Aos meus irmãos, que sempre me apoiaram e estiveram ao meu lado.

Ao meu irmão Daniel, que mesmo sem saber, sem perceber, sempre foi fonte da minha inspiração pela luta na psiquiatria.

Ao Vinícius, que plantou comigo esse sonho de estudar desde criança.

Ao meu pai que, dentro de suas possibilidades, me ofereceu força.

À banca examinadora, por fazer parte de todo esse processo de aprendizado

A todos da equipe do CAPS II por toda a recepção, paciência e ajuda.

À Escola de Enfermagem de Ribeirão Preto e ao Programa de Enfermagem Psiquiátrica, onde foi possível realizar um sonho, o Mestrado.

Aos amigos que adquiri ao longo da minha formação profissional e pessoal: Pebê, Luana, Eduarda, Kleber, Flor, Gandhi e Nathássia, grata por todo o carinho e auxílio ao longo dessa jornada, oferecendo apoio e ótimas gargalhadas

Aos professores, que participaram da minha formação. 
Ainda que eu falasse a língua dos homens E falasse a língua dos anjos Sem amor eu nada seria.... É preciso amar as pessoas Como se não houvesse amanhã Porque se você parar pra pensar Na verdade não há.... 


\section{RESUMO}

Gomes, Dayane Rosa Alvarenga Silva. Estigma internalizado em pacientes com transtorno de humor e fatores associados. 2018. 78f. Dissertação (Mestrado) - Escola de Enfermagem de Ribeirão Preto, Universidade de São Paulo, Ribeirão Preto, 2018.

Nos transtornos de humor, o estigma internalizado (internalização de estereótipos depreciativos associados a uma condição) é desafiador e prejudicial para a reabilitação e qualidade de vida do indivíduo. O presente estudo tem como objetivo investigar o estigma internalizado e as associações entre essa variável e as variáveis sociodemográficas e clínicas, além da esperança e adesão ao tratamento entre pessoas com transtornos de humor. Este estudo com abordagem quantitativa foi realizado com uma amostra de conveniência de 108 pacientes com transtornos de humor, em tratamento em um Centro de Atenção Psicossocial no interior de São Paulo - Brasil. Na coleta de dados foram aplicados os instrumentos: ISMIBR para investigar o estigma internalizado; MAT para investigar a adesão ao tratamento, EEH para analisar a esperança; aplicação da BPRS-a para observar a sintomatologia dos pacientes, e um questionário com questões sociodemográficas e clínicas. Na análise de dados foram empregados testes de comparação de média, teste de correlação e regressão linear múltiplo. Neste estudo predominam mulheres, sem ensino superior, sem companheiro, sem trabalho. A maioria tinha transtorno afetivo bipolar, era aderente ao tratamento medicamentoso, referiu internações psiquiátricas e tentativas prévias de suicídio e negou episódios de heteroagressão. Na amostra investigada, maiores níveis de estigma estiveram associados à maior sintomatologia, menor nível de esperança, tentativas prévias de suicídio, histórico de comportamento agressivo, internações psiquiátricas, não adesão ao tratamento e não ter trabalho. No modelo de regressão linear múltiplo estiveram associadas ao estigma as variáveis trabalho, tentativas de suicídio, sintomas e esperança. Nesse estudo foram identificados fatores que podem conferir ao indivíduo maior vulnerabilidade ao estigma internalizado e que precisam ser cuidadosamente investigados e abordados em intervenções voltadas para a redução do estigma e à reabilitação psicossocial.

Palavras-chave: Esperança. Transtornos de humor. Adesão à medicação. Estigma social. Preconceito. 


\begin{abstract}
Gomes, Dayane Rosa Alvarenga Silva. Internalized stigma in patients with mood disorder and associated factors. 2018. 78f. Dissertation (Master degree) - School of Nursing of Ribeirão Preto, University of São Paulo, Ribeirão Preto, 2018.

In mood disorders, the internalized stigma (internalization of derogatory stereotypes associated with a condition) is challenging and detrimental to the individual's rehabilitation and quality of life. The present study aimed to investigate the internalized stigma and the associations between these variables and sociodemographic, clinical variables, as well as hope and adherence to treatment among people with mood disorders. This quantitative approach was carried out with a convenience sample of 108 patients with mood disorders undergoing treatment at a Psychosocial Care Center in the interior of São Paulo - Brazil. In the data collection, the following instruments were applied: ISMI-BR to investigate internalized stigma; MAT to check adherence to treatment, EEH to examine the hope and application of BPRS-a to observe patient's symptomatology and a questionnaire with sociodemographic and clinical issues. In the data analysis, mean comparison, correlation test, and multiple linear regression tests were used. In this study, women predominated, without higher education, without a partner, without work. Most of them presented bipolar affective disorder, adhered to drug treatment, reported psychiatric hospitalizations and previous suicide attempts, and denied episodes of heteroaggression. In the sample investigated, higher levels of stigma were associated with greater symptomatology, lower level of hope, previous attempts of suicide, history of aggressive behavior, psychiatric hospitalizations, non-adherence to treatment and not having a job. In the multiple linear regression model, the variables labor, suicide attempts, symptoms, and hope were associated with the stigma. In this paper, were identified factors that may give the individual greater vulnerability to internalized stigma and which need to be carefully investigated and addressed in interventions or aiming at reducing stigma and psychosocial rehabilitation.
\end{abstract}

Keywords: Hope. Mood disorders. Medication adherence. Social stigma. Prejudice. 


\section{RESUMEN}

Gomes, Dayane Rosa Alvarenga Silva. Estigma internalizado en pacientes con trastorno de humor y factores asociados. 2018. 78f. Disertación (Master) - Colegio de Enfermería de Ribeirão Preto, Universidad de São Paulo, Ribeirão Preto, 2018.

En los trastornos de humor, el estigma internalizado (internalización de estereotipos despectivos asociados a una condición) es desafiante y perjudicial para la rehabilitación y calidad de vida del indivíduo. El presente estudio tuvo como objetivo investigar el estigma internalizado y las asociaciones entre esa variable y variables sociodemográficas, clínicas, esperanza y adhesión al tratamiento entre personas con trastornos del humor. Este estudio con abordaje cuantitativo fue realizado con una muestra de conveniencia de 108 pacientes con trastornos de humor en tratamiento en un Centro de Atención Psicosocial en el interior de São Paulo - Brasil. En la recolección de datos se aplicaron los instrumentos: ISMI-BR para investigar el estigma internalizado; MAT para investigar la adhesión al tratamiento, EEH para investigar la esperanza y la aplicación de la BPRS-a para investigar la sintomatología de los pacientes y un cuestionario con cuestiones sociodemográficas y clínicas. En el análisis de datos se utilizaron pruebas de comparación de media, prueba de correlación y regresión lineal múltiple. En este estudio predominaron mujeres, sin enseñanza superior, sin compañero, sin trabajo, residía con alguien. La mayoría tenía un trastorno afectivo bipolar, era adherente al tratamiento medicamentoso, refirió internaciones psiquiátricas y intentos previos de suicidio y negó episodios de heteroagresión. En la muestra investigada, mayores niveles de estigma estuvieron asociados a mayor sintomatología, menor nivel de esperanza, intentos previos de suicidio, historial de comportamiento agresivo, internaciones psiquiátricas, no adhesión al tratamiento y no tener trabajo. En el modelo de regresión lineal múltiple, estuvieron asociadas al estigma las variables trabajo, intentos de suicidio, síntomas y esperanza. En este estudio se identificaron factores que pueden conferir al indivíduo mayor vulnerabilidad al estigma internalizado y que necesitan ser cuidadosamente investigados y abordados en intervenciones dirigidas a la reducción del estigma y la rehabilitación psicosocial.

Palabras-clave: Esperanza. Trastornos del estado de ánimo. Adherencia a la medicación. Estigma social. Prejuicio. 


\section{LISTA DE TABELAS}

Tabela 1 - Caracterização sociodemográfica dos participantes do estudo

Tabela 2 - Distribuição dos participantes do estudo segundo aspectos clínicos, adesão e esperança

Tabela 3 - Escores obtidos na escala Estigma Internalizado - ISMI-BR e suas subcategorias

Tabela 4 - Distribuição dos participantes do estudo segundo a variável BPRS-a 36

Tabela 5 - Distribuição dos participantes do estudo segundo o teste de comparação de médias entre as variáveis e as sub-categorias da Escala de Avaliação do Estigma Internalizado ISMI-BR

Tabela 6 - Distribuição dos participantes do estudo segundo a correlação entre as subcategorias da Escala de Avaliação do Estigma Internalizado ISMI-BR com as demais variáveis.

Tabela 7 - Distribuição dos participantes do estudo segundo a comparação de médias entre estigma internalizado e as variáveis sociodemográficas e clínicas

Tabela 8 - Distribuição dos participantes do estudo segundo a correlação entre estigma internalizado e as variáveis sociodemográficas e clínicas

Tabela 9 - Distribuição dos participantes do estudo segundo o modelo de regressão linear múltiplo - variável dependente: Estigma internalizado 


\section{LISTA DE SIGLAS}

APA - American Psychiatric Association

AVI - Anos Vividos com Incapacidade

BPRS-a - Escala de Avaliação Psiquiátrica Breve Anconrada

CAPS - Centros de Atenção Psicossocial

CESD - Centro de Estudo Epidemiológicos

CID 10 - Classificação Internacional das Doenças edição número 10

EAER - Escala de Autoestima de Rosenberg

EEH - Escala de Esperança de Herth

IC - Intervalo de confiança

ISMI-BR - Escala de Estigma Internalizado

MAT - Escala de Medida de Adesão ao Tratamento

OMS - Organização Mundial de Saúde

SIG-BPRS - Structured Interview Guide for BPRS

SPSS - Statistical Package for Social Science

TAB - Transtorno Afetivo Bipolar

TCLE - Termo de Consentimento Livre Esclarecido

UPA - Unidade de Pronto Atendimento

WHO - World Health Organization 


\section{SUMÁRIO}

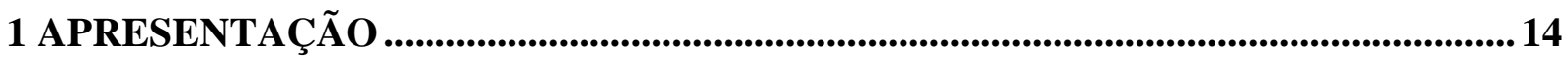

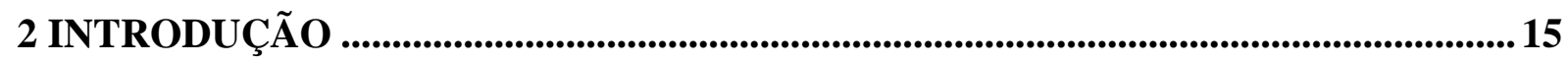

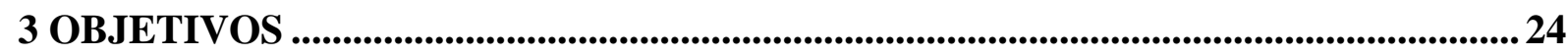

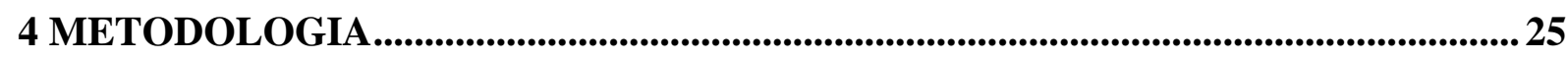

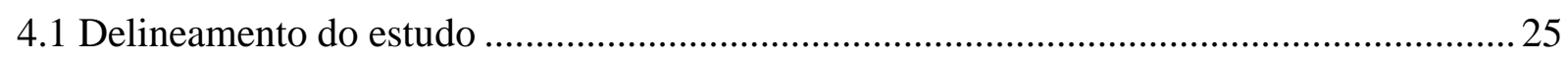

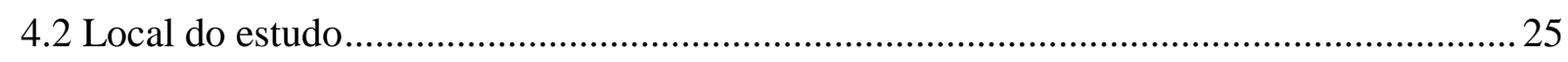

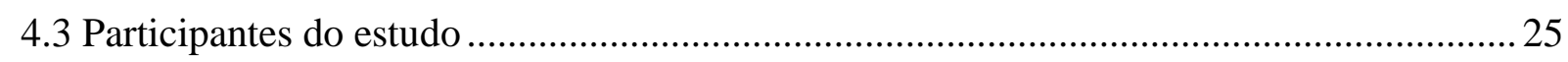

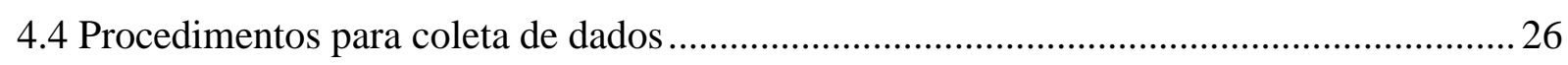

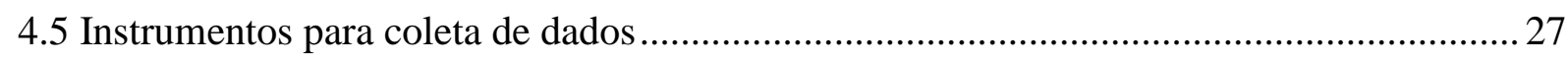

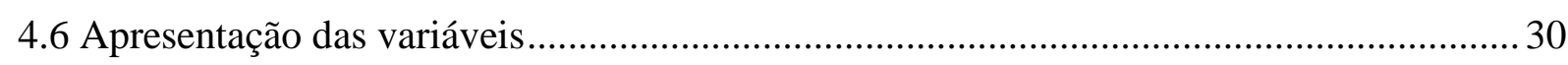

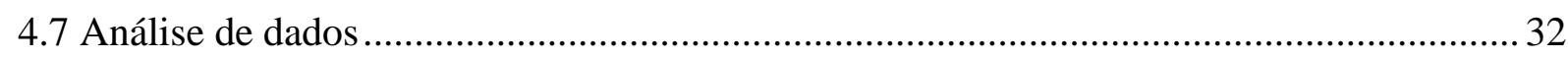

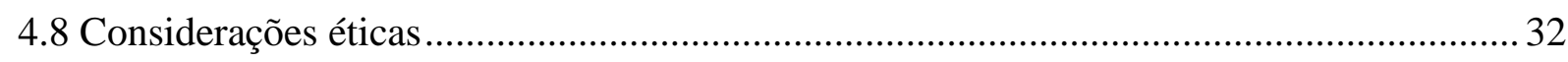

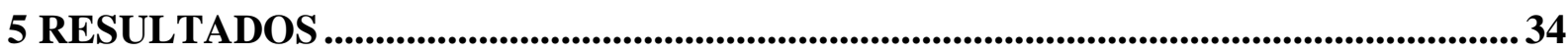

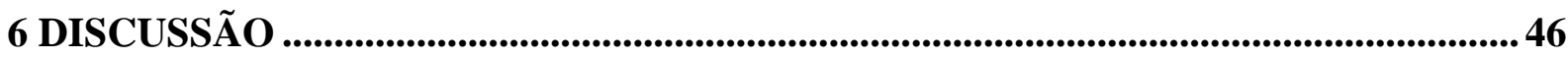

7 CONCLUSÃO

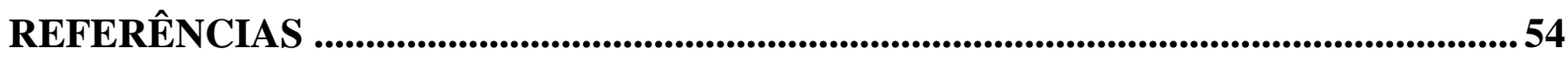

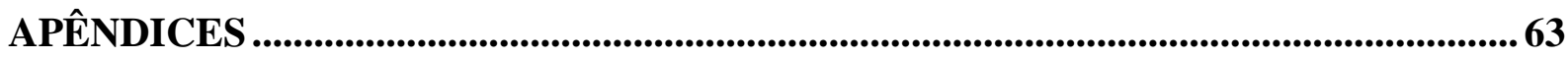

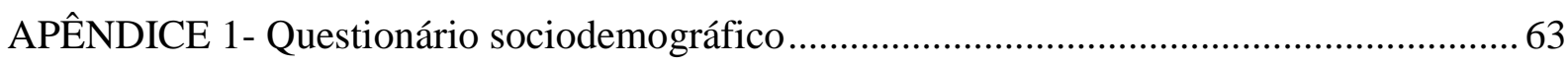

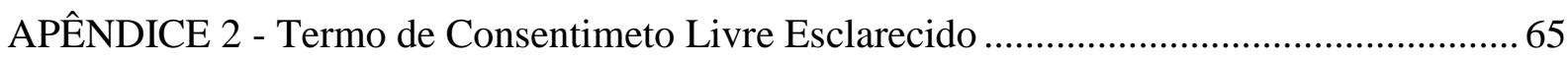

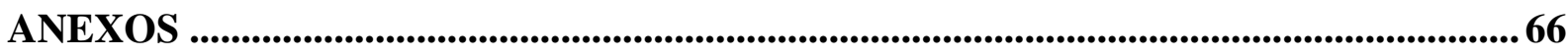

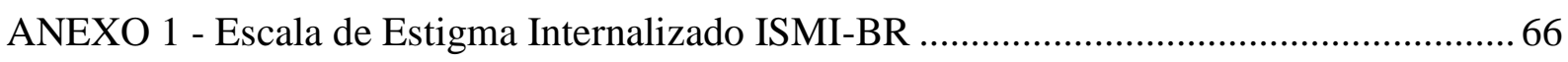

ANEXO 2 - Autorização para o uso da Escala de Estima Internalizado ISMI-BR ................. 68

ANEXO 3 - Escala de Medida de Adesão ao Tratamento MAT .............................................69

ANEXO 4 - Escala de Avaliação Psiquiátrica Breve Ancorada BPRS-a (modificada) .......... 70 
ANEXO 5 - Guia de aplicação da Escala de Avaliação Psiquiátrica Breve Ancorada BPRS-a (modificada).

ANEXO 6 - Autorização para o uso da Escala de Avaliação Psiquiátrica Breve Ancorada

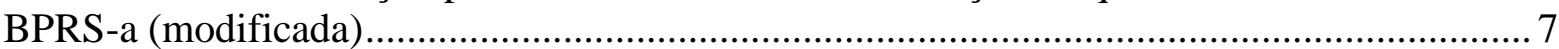

ANEXO 7 - Escala de Esperança de Herth EEH ............................................................ 76

ANEXO 8 - Autorização para o uso da Escala de Esperança de Herth EEH .......................... 77 


\section{APRESENTAÇÃO}

Acredito que nunca fui eu quem escolheu a psiquiatria, mas sim ela que me escolheu. Quando eu tinha nove anos meu irmão mais velho foi diagnosticado com esquizofrenia. Minha mãe, como uma pessoa muito cuidadora, nunca permitiu que ele fosse internado e cuidou dele com intenso zelo em cada surto, em cada dificuldade, em cada nova barreira imposta pela doença, e me inspirou com tamanho carinho - e graças a Deus ele hoje está estável.

Cresci em meio a muito sofrimento e amadurecimento, porém acabei desenvolvendo TOC (Transtorno Obsessivo Compulsivo) aos 12 anos. Nesse momento, mais uma vez, deparei-me com a psiquiatria, com suas dificuldades e seu sofrimento. Encontrei em Deus a minha fortaleza e nos estudos o meu refúgio; criei o sonho de ser uma profissional da área da saúde e de estudar na USP (Universidade de São Paulo). Porém, mais uma vez a vida não me permitiu alcançar os meus objetivos de forma fácil. Estudei em escola pública, com um estudo defasado e o TOC me prejudicava muito nos momentos de estudo... tanto que em alguns momentos pensei em desistir. Tentaram sabotar meus sonhos, talvez em uma tentativa de que eu não me frustrasse tanto ao não alcançá-los, tive meus objetivos questionados por professores, familiares e até por profissionais da saúde. Contudo, Deus abençoou e colocou em meu caminho pessoas incríveis. Uma delas é o meu psiquiátrica, que sempre acreditou que eu seria capaz, e também a minha mãe, que sempre me apoiou na busca das minhas metas e sempre esteve ao meu lado.

No ano de 2012, graças a Deus, passei em Enfermagem Bacharel na USP e iniciei os meus estudos. Imaginei que aquele seria um ambiente seguro, contudo, me assustei ao ver a quantidade de alunos com ideias cheias de estereótipos sobre transtornos mentais e pacientes psiquiátricos. Eles nunca imaginaram que ali, na mesma sala, estava alguém que convivia com um transtorno há bastante tempo. A faculdade foi uma fase difícil, estava carregada de problemas familiares e isso só fez agudizar os sintomas do TOC. Confesso que pensei em desistir, porém, mais uma vez, Deus colocou as pessoas certas na minha vida e comecei a ter a disciplina de Saúde Mental, onde encontrei professoras incríveis, como Ana Carolina Zanetti e Edilaine, as quais me proporcionaram espaço para falar sobre a minha doença e, desde então, encarei como uma obrigação pessoal mostrar para as pessoas que os indivíduos com transtornos mentais podem ter sonhos e podem lutar para realizá-los, uma vez que os mesmos são bem mais do que um diagnóstico.

Nessa jornada Deus me agraciou com uma pessoa muito especial para me orientar, a Prof ${ }^{a}$ $\operatorname{Dr}^{\mathrm{a}}$ Kelly, que é uma pessoa iluminada que me acolheu e me ensinou mais do que pesquisa: me ensinou a ser uma pessoa melhor. Muito obrigada a todos que participaram de alguma forma da minha história. 


\section{INTRODUÇÃO}

Segundo Goffman (1988), o estigma pode ser definido como uma característica que torna um indivíduo diferente dos demais em sua categoria e, assim, esse indivíduo deixa de ser considerado "criatura comum" e torna-se um ser de menos valia. O estigma tem grande efeito de descrédito para o estigmatizado e constitui disparidade entre o que a sociedade almeja e espera, e o que de real essa pessoa tem a oferecer. Assim, pode-se dizer que o estigma refere-se a atributos, na sua maioria depreciativos e incompatíveis, associados a um estereótipo que é atribuído a determinado tipo de indivíduo (CLEMENTE et al., 2015; GOFFMAN, 1988). O estigma gera a exclusão social, perda de status, estereótipos e discriminação nas situações cotidianas - que influencia o indivíduo estigmatizado em suas atitudes, comportamentos e autopercepção sobre as próprias capacidades (MATHIAS et al., 2015). O estigma pode reduzir as chances e as oportunidades sociais de pessoas com transtornos mentais (OLIVEIRA et al., 2015a).

O estigma em relação aos transtornos mentais é algo presenciado em diferentes culturas e está enraizado na sociedade. Ele é multifatorial e pode ser descrito em três níveis de relacionamento interpessoal: estrutural (ou estigma institucional), social (ou estigma público) e individual (estigma internalizado) (CORRIGAN et al., 2005a; OLIVEIRA et al., 2015b).

O nível estrutural envolve um nível macro que diz respeito à restrição de direitos das pessoas com transtornos mentais em relação a políticas, instituições, normas ou regras em geral. O estigma estrutural envolve políticas institucionais e procedimentos que limitam o acesso das pessoas a seus direitos (CORRIGAN et al., 2005a, 2005b; OLIVEIRA et al., 2015b).

O estigma no nível social é quando uma parcela da sociedade, um grupo social, endossa estereótipos sobre um grupo estigmatizado (CORRIGAN et al., 2005a) - e ocorre como resultado de estereótipos negativos, preconceitos e discriminação em relação aos pacientes psiquiátricos (OLIVEIRA et al., 2015a).

Já o estigma internalizado, ou autoestigma, é quando os indivíduos acreditam nos rótulos associados à sua condição e endossam os estereótipos como algo relevante para a autoacreditação e autovalorização (CORRIGAN et al., 2005a). O estigma internalizado consiste no descrédito do indivíduo relacionado à sua própria condição, o que se caracteriza como aceitação e introjeção do preconceito alheio (SEMRAU, et al., 2015). Esse tipo de estigma resulta de um alto nível de insegurança (KANWAR, 2015). 
Howland et al. (2016) dizem que a internalização do estigma ocorre em passos: o primeiro seria a percepção e consciência de estereótipos sociais; o segundo seria aceitar e concordar com tais estereótipos; o terceiro passo seria o endossamento e a aplicação desses estereótipos para si; e o quarto e último passo seria o sofrimento gerado pelo estigma internalizado e tem como consequência uma diminuição da autoestima. A internalização do estigma é uma das consequências negativas para os indivíduos estigmatizados. Ela ocorre à medida em que a pessoa adquire consciência da sua condição de saúde (FELICISSIMO, et al., 2013) e tem a percepção de estar sendo tratada com desvalorização e rejeição. O autopreconceito e a autodescriminação surgem quando o indivíduo passa a concordar com o estereótipo vinculado a si mesmo (OLIVEIRA et al., 2015b) e aplica a si as rotulagens negativas relacionadas à própria condição psíquica (FELICISSIMO, et al. 2013).

O estigma internalizado pode propiciar o comportamento de estigmatizado mesmo com o desaparecimento dos sintomas dos transtornos mentais (OLIVEIRA et al., 2015b; CLEMENT, et al., 2015).

O estigma internalizado também pode ocorrer de forma antecipatória, ou seja, o indivíduo com transtorno mental pode ter expectativas de sofrer estigma por parte da sociedade e antes de experimentar a discriminação pode adotar estratégias de proteção (SEMRAU, et al., 2015).

A vivência de ser estigmatizado e a conscientização do estigma devido à condição psíquica são experiências dolorosas e associadas à revolta, desesperança, sofrimento e danos para a autoestima, o que contribui para um comportamento de autodesvalorização, vergonha e isolamento (OLIVEIRA et al., 2015b). Outra consequência do estigma consiste na percepção, conscientização e sua internalização; a partir dessas vivências o indivíduo passa por situações como perda da identidade, limitação das oportunidades e dificuldade de acesso aos serviços de saúde, bem como sente o impacto negativo em aspectos psicossociais como no funcionamento social, na esperança e autoeficácia (FELICISSIMO et al., 2013). Os transtornos mentais atualmente representam importante causa de morbidade e mortalidade, constituindo um grande desafio para os serviços de saúde em todo o mundo. Segundo a Organização Mundial da Saúde (OMS), 3\% das pessoas sofrem de algum tipo de transtorno mental grave ou persistente e $12 \%$ necessitam de atendimento contínuo ou eventual em serviços de saúde mental no decorrer da vida. Estudos mostram que a prevalência de transtornos mentais, no período de um ano, é de $10 \%$ a $20 \%$ e, ao longo da vida, esse índice aumenta para $20 \%$ a $40 \%$. O transtorno mental caracteriza-se como uma ruptura e/ou dano na saúde mental do indivíduo, e tem papel importante na redução da qualidade de vida e da 
produtividade do paciente. Dessa maneira, os transtornos mentais geram problemas na esfera da saúde pública e afetam, também, o setor econômico (COUTINHO et al., 2014; WHO, 2001, 2009; KESSLER et al., 2009; BINOTTO, 2014).

Dentre os transtornos mentais, nesse estudo serão enfocados aqueles que afetam o humor e que têm como perturbação fundamental a alteração do humor e do afeto, resultando em episódio depressivo, que muitas vezes pode aparecer acompanhado de ansiedade ou elevação do humor. Essas alterações são, comumente, acompanhadas por uma modificação no nível global de atividade. São transtornos crônicos que, na sua maioria, manifestam exacerbação de seus sintomas de forma recorrente, períodos esses denominados como recaídas ou surtos. Esses períodos podem estar associados com situações ou fatores estressantes (OMS, 2008; ABREU, 2015).

Há associação entre os transtornos de humor e redução da qualidade de vida, prejuízo no desempenho social, ocupacional, acadêmico, maior risco de suicídio e comorbidades com outros transtornos mentais e má evolução de doenças clínicas concomitantes, pois são transtornos que trazem grande aflição e sofrimento aos pacientes (OMS, 2008; ABREU, 2015)

Os principais e mais estudados transtornos do humor são o transtorno depressivo e o transtorno afetivo bipolar (OMS, 2009). Os primeiros são caracterizados por rebaixamento do humor e diminuição do nível de energia e funcionalidade, juntamente com a presença de tristeza por, no mínimo, duas semanas consecutivas. Há, também, perda de interesse e prazer nas atividades, apatia, irritabilidade, retraimento social e choro fácil. Na maioria dos casos, há uma autodesvalorização com constante sentimento de culpa, e tal sentimento pode ir desde a sensação de desvalia à culpabilidade delirante. Sintomas somáticos podem estar presentes, tais como: perturbações do sono, diminuição da libido, sensação de dor física, alterações de apetite e da psicomotricidade, fadiga e pensamento lentificado, com dificuldade de concentração e na tomada de decisões (OMS, 2008; APA, 2014).

No transtorno depressivo existe a permanente possibilidade de suicídio, com chance maior que nos demais transtornos, pois a ideação suicida e o sentimento de desesperança são constantes no decorrer da agudização dos sintomas. Esse fato faz com que a depressão esteja associada com alta mortalidade. Existe a possibilidade de prejuízo grave na funcionalidade do indivíduo com perda total de sua capacidade no gerenciamento de suas necessidades básicas. Comumente há negligência para o autocuidado e, em casos mais graves, mutismo e catatonia. Por isso, trata-se de um transtorno com grande redução no funcionamento físico, emocional e social, podendo ocorrer perda de papéis do indivíduo na sociedade (APA, 2014). 
A depressão tornou-se problema de saúde pública acometendo 350 milhões de pessoas em um período de 12 meses, e a prevalência de depressão no Brasil corresponde a 10\% desse valor (RAZZOUK, 2016) - fatos que reforçam a importância de estudos sobre o tema. Atualmente, a depressão é a principal causa de incapacidade, mensurada por anos vividos com incapacidade (AVI), e a segunda causa de anos de vida perdidos ajustados com incapacidade (AVAIs), na faixa etária de 15 a 44 anos (WHO, 2012).

O transtorno bipolar é outro tipo de transtorno no qual as oscilações do humor e a perturbação no nível de atividade do indivíduo manifestam-se por meio de episódios de elevação de humor e energia (mania, hipomania) e episódios com diminuição do humor e do nível de energia (depressão) (OMS, 2008).

Nos episódios de mania há uma elevação anormal do humor por elevados períodos, com expansividade do humor e aumento da energia e nível global de atividade, que caracterizam o humor eufórico. Há, também, aumento da produtividade e da autoestima do indivíduo, podendo chegar a uma autoconfiança sem percepção de autocrítica a uma grandiosidade delirante. $\mathrm{O}$ transtorno bipolar gera sérios danos ao paciente, que perde o insight e o juízo crítico, gerando prejuízo social e emocional, causando a $30 \%$ dos pacientes sérios danos em sua vida profissional (APA, 2014). A literatura estima que a prevalência de transtorno bipolar seja cerca de $2 \%$ da população, e esse número chega a $5 \%$ quando se considera o espectro bipolar. Acredita-se que essa prevalência seja maior, pois o TAB é, geralmente, subdiagnosticado ou erroneamente tratado como transtorno depressivo unipolar (SOUZA, 2014; SCUSSEL et al., 2016). Estima-se, também, que esses indivíduos têm 15 vezes maior chance de cometer suicídio do que a população em geral; o sofrimento que o transtorno bipolar pode causar é tamanho que corresponde a $25 \%$ de todos os suicídios (APA, 2014) - fatos que só corroboram com a importância de se trabalhar com a temática.

Pessoas com transtornos de humor, além do sofrimento experimentado pelos seus sintomas e limitações decorrentes, podem experimentar problemas com o estigma relacionado ao transtorno mental que pode trazer determinado nível de incapacidade e estar associado a rótulos como "frescura", "preguiça", "desanimo", "promiscuidade" e "desvio de conduta" (CLEMENTE, 2015).

Diversos estudos têm buscado compreender melhor a relação entre o estigma internalizado e a adesão ao tratamento de condições clínicas e transtornos mentais potencialmente estigmatizantes. Uma importante parcela dos estudos preocupa-se com a influência que esse estigma pode exercer sobre a busca ou continuidade do tratamento. $\mathrm{O}$ estigma internalizado está associado à baixa autoestima e medo de estereótipos, o que pode 
resultar em relutância para procurar ajuda e aceitar o diagnóstico, atraso na procura de tratamento e baixa adesão ao tratamento - tanto psicossocial quanto farmacológico (PICCO et al., 2016).

O estigma também interfere na busca e manutenção de redes de apoio, pois as experiências estigmatizantes podem levar o indivíduo a não revelar sua condição psiquiátrica por medo de maiores represálias (MASCAYANO; ARMIJO; YANG, 2015), por vergonha, medo de ser rotulado (SHRIVASTANA et al., 2013), sofrer preconceito (HANAFIAH; BORTEL, 2015) ou ser excluído dos círculos sociais (MESTDAGH; HANSEN, 2014). Ademais, ser diagnosticado com um transtorno mental é estressante e estigmatizante tanto para o paciente quanto para os familiares. Todos esses aspectos podem contribuir para esforços direcionados no sentido de se esconder os sintomas dos transtornos mentais, bem como à resistência na busca por tratamento (KAMARADOVA et al., 2016).

O impacto negativo do estigma sobre a adesão ao tratamento farmacológico pode ser especialmente importante nos transtornos de humor, pois a adesão aos medicamentos destacase como um fator potencialmente modificável na busca de melhora do prognóstico dos pacientes (BUSBY; SAJATOVIC, 2010). Barney et al (2009) provaram que as estratégias criadas pelos indivíduos para evitar o estigma é o obstáculo mais importante para receber ajuda no tratamento, por isso, a busca de maiores estudos para compreender o paradigma entre estigma internalizado e adesão faz-se necessária.

A literatura sugere que a não adesão também pode estar associada a maior estigma. Com a interferência negativa do estigma internalizado na manutenção do tratamento medicamentoso (KANWAR, 2015; HANAFIAH; BORTEL, 2015; SEMRAU et al., 2015) o processo de reabilitação fica prejudicado e ineficaz (KANWAR, 2015). A ausência de tratamento adequado faz com que os sintomas psiquiátricos fiquem mais evidentes, o que pode resultar em comportamentos não aceitos socialmente e acentuação do estigma prejudicando, ainda mais, a qualidade de vida e autoestima do estigmatizado (HANAFIAH; BORTEL, 2015). Além disso, o polo de humor depressivo interfere diretamente na não adesão ao tratamento devido ao alto nível de desesperança e baixo poder de autoeficácia que ele gera (KAMARADOVA et al., 2016; PRASKO et al., 2016).

O conceito de adesão está associado ao grau que os indivíduos adotam as recomendações fornecidas para o próprio tratamento, tanto no contexto psicológico quanto medicamentoso. Segundo a OMS, adesão ao tratamento refere-se à aceitação e cumprimento das recomendações feitas por profissionais de saúde para determinado tratamento (OMS, 2003). A não adesão parcial ou total está associada à pior reabilitação, piores resultados 
clínicos, internações, maiores custos e maior número de suicídio (UHLMANN et al., 2014; SEDLACKOVA et al., 2015).

A literatura revela que a não adesão ao tratamento dos transtornos de humor favorece o retorno dos sintomas e à refratariedade farmacológica (SANSONE, SANSONE, 2012; ALHARBI, 2012; BUSBY; SAJATOVIC, 2010; POMPILI et al., 2009), recaídas (MCALLISTER-WILLIAMS, FERRIER, 2009), hospitalizações e aumento das tentativas de suicídio (POMPILI et al, 2009), além de propiciar a ineficácia do tratamento e prejuízos na economia do indivíduo e, em uma visão macro do problema, do país. Estudos mostram que a maioria dos pacientes com depressão ou transtorno bipolar não adere à prescrição medicamentosa (SANSONE; SANSONE, 2012; BUSBY; SAJATOVIC, 2010; CRUZ et al., 2011; MIASSO et al., 2011; ZAGO et al., 2015). O descrédito de que o tratamento pode fornecer apoio e ajuda é um dos fatores que leva o indivíduo com estigma internalizado à não aderência ao tratamento (KAMARADOVA et al., 2016; PRASKO et al., 2016).

As internações psiquiátricas e a manifestação de comportamento agressivo parecem ser importantes fatores relacionados ao estigma internalizado. Historicamente, as internações psiquiátricas constituíram-se em formas de segregação, discriminação, alienação e violação de direitos humanos de pessoas consideradas anormais ou inaptas para a vida em sociedade (GOFFMAN, 1988).

Atualmente, as internações psiquiátricas podem ser consideradas benéficas e necessárias em algumas situações, contudo podem ser um forte estressor para o paciente. Elas são carregadas de estereótipos, associadas à maior gravidade de sintomas, periculosidade e perda do autocontrole (MOSES, 2014).

A crença de que pacientes com transtornos mentais sejam perigosos para si e para terceiros e requeiram reclusão pode gerar incertezas sobre o próprio autocontrole mediante estressores e fazer com que os mesmos internalizem dúvidas e inseguranças que futuramente, se não contraditas, tornam-se fomento para o estigma internalizado (MOSES, 2014; VEDANA et al., 2017).

A literatura aponta ainda que o sentimento de perda de controle sobre as próprias ações está associado tanto às internações psiquiátricas quanto aos episódios de heteroagressão e ambos estão ligados à desvalorização de si mesmo, autodepreciação, menor empoderamento e estigma internalizado. Quando o indivíduo internaliza sentimentos e percepções associados a internações e aos episódios heteroagressivos, pode experimentar consequências negativas duradouras, que são vivenciadas mesmo após a alta e remissão de sintomas (XU et al., 2018). 
Isso favorece que o indivíduo com um transtorno mental se perceba com uma doença incontrolável e permanente (HARRIS et al., 2015).

$\mathrm{Na}$ literatura predomina a investigação da influência do estigma sobre o comportamento suicida entre pessoas com transtorno de humor. Esse estudo, contudo, pretende trabalhar o assunto sob uma perspectiva diferente ao abordar as tentativas de suicídio como possíveis preditoras de estigma internalizado, que pode propiciar solidão, baixa autoestima e desesperança, aspectos que são considerados fatores de risco para o comportamento suicida entre portadores de transtornos mentais (idem, 2015).

Os transtornos mentais são a ligação mais preocupante e forte entre o estigma e o suicídio, onde muitas vezes o suicídio é visto como uma maneira de acabar com todo o estresse e sofrimento causado pelo estigma. Uma das explicações sobre a associação entre o estigma internalizado e o suicídio seria o isolamento social que gera no indivíduo o sentimento de desamparo e o faz perceber-se como uma pessoa sem apoio social e emocional. Outra explicação seria a baixa autoestima causada pelo estigma internalizado que está relacionada a sentimentos de desprezo e desesperança. $\mathrm{O}$ estigma como barreira na busca de ajuda também é um fator que contribui para a associação entre o estigma internalizado e o suicídio (CARPINELLO; PINNA, 2017).

Ao falar de suicídio e transtornos mentais é possível destacar uma relação entre o suicídio e os transtornos de humor, uma vez que o polo depressivo está fortemente associado a maiores tentativas de suicídio. O aspecto imprevisível e impulsivo dos transtornos de humor também são fatores de risco para o comportamento suicida. A oscilação e a instabilidade do humor também estão associadas a um maior risco para as tentativas de suicídio (BOBO et al., 2018; WANG et al., 2017). Estudos longitudinais concluíram que após um ano de exposição ao estresse do estigma internalizado os indivíduos começaram a ter ideação suicida (OEXLE et al. 2016; XU et al. 2016).

O suicídio é um fenômeno multifatorial e tornou-se um problema de saúde pública no mundo: é a $15^{\mathrm{a}}$ causa de morte e mais de 800 mil pessoas tiram a própria vida todos os anos. O suicídio representa 1,8\% da carga global de doenças (CARPINELLO; PINNA, 2017; FARRELLY et al., 2015). Portadores de transtornos mentais são mais vulneráveis ao risco de suicídio e $90 \%$ das pessoas que tentam ou concluem o suicídio têm algum transtorno mental (WANG et al., 2017) A maioria das mortes por suicídio pode ser evitadas com identificação e intervenção precoce (LIU et al., 2015), por isso, estudos que explorem a relação entre o estigma internalizado e as tentativas de suicídio são necessários e importantes para a elaboração de intervenções preventivas. 
Outro elemento importante a ser explorado é a relação entre o estigma internalizado sobre a esperança, tida como um passo vital para a recuperação, pois está ligada à expectativa ou desejo de eventos positivos no futuro, tornando-se a força motriz para impulsionar a vontade de se autoajudar. A esperança fornece maior poder adaptativo para as pessoas superarem obstáculos, e é um conceito que abrange várias dimensões e que está ligado a conforto, segurança e significado da vida. Ela proporciona ao indivíduo uma visão durável da vida, com propósitos e objetivos. É uma força motivadora que molda o futuro, fazendo com que o indivíduo supere um momento frágil e de vulnerabilidade, obtendo um olhar mais pleno e satisfatório (HAYES et al., 2017).

A esperança baseia-se em gerenciamento de determinação para alcançar objetivos e metas e é associada à confiança e motivação, elementos que fornecem a sustentabilidade no trajeto de conquista dos objetivos e metas estabelecidos. Além disso, a esperança promove a motivação para viver e é um importante recurso pessoal para enfrentar estressores da vida. A manutenção da esperança está diretamente ligada a relações interpessoais e conexões do indivíduo, pois essas tornam-se alicerces para o indivíduo sempre almejar atingir seguir um passo adiante (POTTER, 2013; CLAYTON, 2008; SNYDER, 2002).

Ser diagnosticado com uma doença crônica pode mudar a maneira de perceber a própria vida e pode conduzir para percepções de perda de expectativas positivas relacionadas ao futuro (MACDOUGALL; VANDERMEER; NORMAN, 2015). Todavia, assim como todo indivíduo, a pessoa com transtorno mental precisa de um propósito na vida; precisa se sentir valorizado e ter uma percepção positiva de si mesmo, por isso a esperança torna-se um aspecto importante para a vida desse paciente e torna-se, também, uma ferramenta no enfrentamento do estigma internalizado (SALLES; BARROS, 2013; MACDOUGALL; VANDERMEER; NORMAN, 2015). A esperança do indivíduo sobre o que ele poderia se tornar no futuro pode ter impacto na sua autoestima, emoção e motivação, assim, a percepção do transtorno mental como algo limitador está relacionada à consciência da perda de um futuro próspero (MACDOUGALL; VANDERMEER; NORMAN, 2015). Ter esperança contribui para a eficácia do plano terapêutico e está relacionada de forma positiva com a melhora do humor e da capacidade para reagir às mudanças impostas pelos transtornos mentais (PRASKO et al., 2016).

A literatura tem demonstrado que o estigma internalizado pode ter impacto negativo na manutenção da esperança e, consequentemente, prejudicar esse aspecto que ajuda significativamente na recuperação do indivíduo com transtorno de humor (PRASKO et al., 2016). Há associação entre estigma internalizado e maiores níveis de desesperança, aspecto 
que impacta negativamente na adesão ao tratamento, na crença de reabilitação do indivíduo e na sua valorização como um ser pensante capaz de atingir determinados graus de independência. Dessa maneira, faz-se importante maiores buscas sobre o impacto do estigma internalizado nos transtornos mentais para melhor compreender esse fenômeno e intervir em suas ações (MOROTE et al., 2017).

O estigma é moldado por manifestações culturais e exerce impacto sobre diferentes esferas da vida da pessoa com transtorno mental. Assim, é um fenômeno que precisa ser investigado em diferentes contextos histórico-culturais e a relação entre estigma e níveis de esperança tem sido pouco abordada no contexto brasileiro. Faz-se necessário entender a percepção que esse indivíduo tem sobre a sua própria condição psíquica e o impacto que essa condição tem em sua vida nos âmbitos da adesão ao tratamento, sintomatologia e esperança (SEMRAU et al., 2015).

A gravidade do transtorno de humor é real, bem como a sobrecarga física e emocional vivenciada pelos pacientes, uma vez que o estigma internalizado potencializa essas experiências negativas traumatizando várias esferas da vida do indivíduo como a esperança, qualidade de vida e até a própria doença. A exposição a estressores aumenta a sintomatologia e essa, por sua vez, interfere nas metas e objetivos de longo e curto prazo do paciente, criando um ciclo vicioso entre exposição ao estigma, sua internalização, redução na qualidade de vida e vice-versa (MOROTE et al., 2017). Por isso, o presente estudo traz novas perspectivas sobre a temática com as relações entre estigma internalizado, a adesão ao tratamento e a esperança, juntamente com a sintomatologia dos transtornos de humor. É necessário que haja investigações para uma melhor compreensão da interação entre esses fenômenos e para elaboração de intervenções que visem à qualificação do cuidado e uma assistência holística.

$\mathrm{Na}$ literatura estão disponíveis trabalhos sobre a relação entre estigma internalizado e transtornos mentais, assim como trabalhos sobre adesão e transtornos mentais, contudo há poucos estudos que investigam, juntamente, o estigma internalizado, a adesão medicamentosa, as tentativas de suicídio, a heteroagressão, a esperança e o transtorno de humor, mais especificamente. Por isso, o presente estudo faz importante contribuição para a literatura, uma vez que investiga a presença e a magnitude de associações entre esses diferentes fatores e o estigma internalizado. Esse conhecimento pode subsidiar o planejamento de estratégias de cuidado, necessárias para a promoção da qualidade de vida dos pacientes e sua reabilitação. 


\section{OBJETIVO}

Este estudo tem como objetivo investigar o estigma internalizado e as associações entre essa variável e variáveis sociodemográficas, clínicas, esperança e adesão ao tratamento entre pessoas com transtornos de humor. 


\section{METODOLOGIA}

\subsection{Delineamento do estudo}

Este estudo tem abordagem quantitativa, ou seja, é baseado em raciocínio dedutivo para criar hipóteses, através de mensuração e análise de variáveis. É realizado de modo sistemático, ou seja, segue um conjunto de etapas pré-definidas para se chegar ao desfecho final e, tal fato, ocorre para se conseguir maior precisão e reduzir vieses (DAL-FARRA; LOPES, 2014).

\subsection{Local do estudo}

A presente pesquisa foi realizada em um serviço localizado no município do interior do estado de São Paulo. Trata-se de um Centro de Atenção Psicossocial (CAPSII) que oferece atendimento multiprofissional em saúde mental em regime de semi-internação ou em sistema de consultas para a maioria dos pacientes cadastrados no serviço (que não estão em semiinternação). As consultas psiquiátricas são realizadas geralmente a cada três meses, podendo ter maior frequência de acordo com a gravidade do quadro clínico do paciente. O serviço atende pessoas com transtornos mentais e respectivos familiares que residam no distrito central do município, com idade a partir de 18 anos, mediante encaminhamento de outras unidades de saúde, tais como UPA e serviços psiquiátricos de internação de longa permanência, entre outros.

O serviço oferece consultas com psiquiátricas, psicólogo, atendimento de enfermagem, oficinas de artesanato e de ginástica postural, além de grupos de "psicodrama", de "ouvidores de vozes" e grupo com familiares uma vez por semana. No serviço de semi-internação o paciente fica todo o período da tarde na instituição, onde recebe alimentação e administração dos medicamentos, participa das atividades oferecidas e, em seguida, é liberado para ir para casa.

\subsection{Participantes do estudo}

Os critérios de inclusão dos participantes do estudo foram: estar em tratamento no local do estudo, ter diagnóstico de transtorno de humor, estabelecido por psiquiatra de acordo com a $10^{a}$ edição da Classificação Internacional de Doenças/CID-10 (OMS, 2000) e ter prescrição de psicotrópicos. Foram considerados critérios de exclusão: ter menos de 18 anos de idade, incapacidade para comunicação verbal em português, diagnóstico de transtornos psicóticos ou dependência química, estar internado em outro serviço de saúde no período da 
coleta de dados, abandono do tratamento (mais de um ano sem passar por consulta médica) e transferência para outro serviço durante o período da coleta de dados.

A população atendida no local do estudo correspondia a 793 pacientes, dos quais 388 tinham diagnóstico de transtornos de humor. Dentre esses pacientes, 32 foram excluídos por terem diagnóstico de transtorno psicóticos e/ou dependência química, 16 abandonaram o tratamento (mais de um ano sem passar por consulta médica), cinco estavam internados, quatro foram transferidos para outro serviço, três se recusaram a participar da pesquisa e um faleceu. Desse modo, eram elegíveis para o trabalho 340 pacientes, que deveriam participar do estudo no próprio serviço, quando comparecessem para alguma consulta ou outra atividade terapêutica. A falta de assiduidade às consultas agendadas (geralmente a cada três meses) trouxe prejuízos à coleta de dados. Assim, nesse estudo foi composta uma amostra de conveniência de 108 pacientes que compareceram ao serviço no período da coleta de dados.

\subsection{Procedimento para coleta de dados}

Inicialmente, foi solicitado o acesso aos prontuários das pessoas atendidas nos locais do estudo. O serviço disponibilizou uma lista que continha o nome e o diagnóstico de todos os pacientes que fazem tratamento no local. Tal lista era composta por 793 pacientes e, destes, 388 tinham diagnóstico de transtornos de humor.

Os prontuários desses 388 pacientes foram analisados manualmente para a composição de uma lista com as pessoas que atendiam aos critérios de seleção do estudo. No prontuário foi realizada a confirmação das informações relacionadas aos critérios de seleção do estudo e houve total sigilo das informações.

O convite para a participação no estudo foi realizado por meio de ligação telefônica ou pessoalmente, no momento em que as pessoas elegíveis para participar da pesquisa estavam no local do estudo para consulta ou participação em outras atividades, e houve prioridade para o convite feito pessoalmente. O horário destinado à coleta foi realizado conforme a preferência do usuário, considerando também o horário de funcionamento do serviço e disponibilidade da pesquisadora. Os indivíduos foram esclarecidos sobre a pesquisa e consentiram, por escrito, em participar do estudo.

A entrevista foi realizada no serviço de saúde, em local privativo, assegurando o sigilo das informações e preservando a intimidade dos participantes. Foram aplicados aos participantes a Escala de Medida de Adesão ao Tratamento (MAT), a Escala de Esperança de Herth (EEH), a Escala de Estigma Internalizado (ISMI-BR), escalas para mensuração de sintomas afetivos e um questionário elaborado pelas pesquisadoras que contém questões 
relacionadas a dados demográficos, socioeconômicos, histórico de saúde e sobre o perfil clínico e farmacoterápico da pessoa com diagnóstico de transtorno de humor. O questionário sociodemográfico e demais instrumentos foram aplicados por pessoas devidamente treinadas. No trabalho houve escalas que podem ser autoaplicáveis e escalas de avaliação que devem, obrigatoriamente, ser aplicadas pelo pesquisador.

As escalas autoaplicáveis são: Escala de Medida de Adesão ao Tratamento (MAT), a Escala de Esperança de Herth (EEH) e a Escala de Estigma Internalizado (ISMI-BR). Para as escalas de autoaplicação foi explicado ao paciente que ele poderia optar por responder os instrumentos sem auxílio ou, se tivesse preferência ou alguma dificuldade, o pesquisador poderia ler as questões para auxiliá-lo. Foi realizada a leitura das questões e respostas, sem interferências na escolha da resposta e sem explicações adicionais sobre os instrumentos. No estudo, a Escala de Avaliação Psiquiátrica Breve Ancorada (BPRS-a) foi, obrigatoriamente, aplicada mediante a avaliação realizada pelo pesquisador, conforme indicado.

Foi realizado um teste piloto com três indivíduos para o ajuste do questionário sociodemográfico, adequação do entrevistador e estimativa de tempo para aplicação dos instrumentos.

\subsection{Instrumentos para coleta dos dados}

\subsubsection{Escala de Estigma Internalizado - ISMI-BR}

O nível de estigma internalizado nos indivíduos foi avaliado por meio da Escala de Estigma Internalizado - ISMI-BR, versão brasileira da Internalized Stigma of Mental Illness ISMI, que foi traduzida e validada por Nery et al. (2013) (Anexo 1).

A escala é tipo Likert contendo 29 afirmativas com opções de respostas: (1) discordo totalmente; (2) discordo; (3) concordo e (4) concordo totalmente. Na escala há agrupamento temático em cinco subescalas: Alienação, Aprovação do estereótipo, Percepção de Discriminação, Evitação Social e Resistência ao Estigma. O escore total varia de 29 a 116, sendo que quanto mais elevado o escore maior o nível de estigma internalizado (NERY et al., 2013).

A fidedignidade do instrumento foi considerada satisfatória, uma vez que o Coeficiente alpha de Cronbach foi de 0,90, o Coeficiente de Spearman-Brown (Split-half) foi 0,86 e a correlação teste reteste 0,80 . Quanto à avaliação da consistência interna referente à correlação entre os componentes do instrumento, o resultado das correlações foi estatisticamente significativo $(\mathrm{p}<0,01)$ e todas as correlações apresentaram índices satisfatórios (NERY et. al., 2013). 
A Escala de Estigma Internalizado para Transtorno Mental apresentou validade convergente satisfatória com a Escala de Autoestima de Rosenberg (EAER), Escala de Esperança de Herth (EEH) e Escala de rastreamento populacional para depressão do Centro de Estudos Epidemiológicos (CES-D) (NERY et. al., 2013).

Foi obtida do autor da versão brasileira a autorização para uso da escala no presente estudo (Anexo 2).

\subsubsection{Escala de Medida de Adesão ao Tratamento (MAT)}

A escala de Medida de Adesão ao Tratamento (MAT) foi utilizada para mensurar a adesão dos indivíduos ao tratamento medicamentoso (Anexo 3). A escala foi construída em língua portuguesa por Delgado e Lima (2001). É uma escala composta por sete itens que avaliam o comportamento do indivíduo em relação à adesão. Cada item possui opções de resposta tipo Likert com pontuação de um a seis. Os valores correspondentes às respostas de cada questão do MAT são somados, divididos pelo número total de questões e o valor encontrado é convertido em escala dicotômica que indica se o informante é aderente ou não aderente ao tratamento medicamentoso. A não adesão ao tratamento corresponde a valores obtidos de um a quatro enquanto valores entre cinco e seis representam a adesão ao tratamento (DELGADO; LIMA, 2001).

No estudo de Delgado e Lima (2001) identificou-se boa consistência interna do MAT no formato de escala de Likert. Em termos de validade concorrente, a medida de adesão apresentou correlações elevadas com o critério de contagem de comprimidos. A resposta em forma de escala de Likert revelou maior sensibilidade $(0,77)$ e especificidade $(0,73)$ para identificar a adesão ao tratamento (idem, 2001).

$\mathrm{Na}$ aplicação da escala foi utilizado o recorte de tempo dos últimos três meses e foi enfatizado que as perguntas eram apenas sobre as medicações utilizadas no tratamento psiquiátrico.

\subsubsection{Escala de Avaliação Psiquiátrica Breve Ancorada (BPRS-a) modificada}

A escala é composta por 18 itens que avaliam diferentes sintomas psiquiátricos que são classificados em cinco níveis de gravidade, sendo eles: 0 - ausente; 1 - muito leve ou com presença duvidosa; 2 - presente em grau leve; 3 - presente em grau moderado; 4 - presente em grau severo ou extremo. A versão ancorada possui definições para os cinco níveis de gravidade (ZUARDI et al., 1994) (Anexo 4).

Para o presente trabalho foi utilizado como guia para as entrevistas realizadas o Structured Interview Guide for BPRS (SIG-BPRS), criado por Crippa et al. (2001) (Anexo 5). 
A fidedignidade da escala foi avaliada através do teste de Correlação Inclasse para os itens individuais, dos fatores e dos escores totais. O Coeficiente de correlação entre as classes da escala foi de 0,91 . A consistência interna da escala foi mensurada através coeficiente alfa de Cronbach's com valor de 0,653. Todos tiveram um valor de fidedignidade estatisticamente significativo com $\mathrm{p}<0,001$ (ZUARDI et. al., 1994; Crippa et al, 2002).

A validade foi aferida através da análise de ROC, onde o melhor escore $(<6)$ apresentou sensibilidade de 0,92 e especificidade de 0,73 (ZUARDI et. al., 1994).

O estudo mostra que a validação da escala teve fidedignidade e validade satisfatória. Foi obtida do autor da versão brasileira a autorização para uso da escala no presente estudo (Anexo 6).

A escala foi empregada no presente estudo para avaliar a sintomatologia do paciente. Este dado se constitui em informação relevante para investigar possíveis associações com outras variáveis do estudo, bem como para garantir maior fidedignidade das informações.

4.5.4 A Escala de Esperança de Herth (EEH)

A Escala de Esperança de Herth (EEH) é um instrumento de fácil e rápida aplicação que mensura o nível de esperança dos indivíduos. Essa é uma escala composta por 12 itens escritos de forma afirmativa tipo Likert de quatro pontos, variando de um a quatro, onde um indica "discordo completamente" e quatro indica "concordo completamente". A afirmação de número três e a de número seis apresentam escores invertidos. O escore total varia de 12 a 48 sendo que quanto maior o escore, mais alto o nível de esperança (SARTORE; GROSSI, 2008) (Anexo 7).

O instrumento foi construído por Herth nos Estados Unidos em 1992 e foi traduzido e validado para o contexto brasileiro por Sartore e Grossi, em 2008. A escala apresentou consistência interna com resultados satisfatórios do coeficiente Alpha de Cronbach, um total de 0,834 . O teste-reteste mostrou que a média dos índices obtidos entre aplicações obteve valor similar ( $\mathrm{p}=0,97)$ (SARTORE; GROSSI, 2008).

A validade de construto foi confirmada por meio da validade convergente entre a Escala de Esperança de Herth e a Escala de Autoestima de Rosenberg e pela validade divergente entre a Escala de Esperança de Herth e o Inventário de Depressão de Beck (SARTORE; GROSSI, 2008).

Foi obtida do autor da versão brasileira a autorização para uso da escala no presente estudo (Anexo 8).

4.5.5 Questionário sociodemográfico e clínico 
Será aplicado aos participantes um questionário elaborado pelas pesquisadoras que contem questões relacionadas a dados demográficos, socioeconômicos, histórico de saúde, perfil clínico e farmacoterápico da pessoa com diagnóstico de transtorno de humor. Além de questões sobre se houve internações psiquiátricas e sua quantidade; se houve tentativas de suicídio e sua quantidade e se já houve episódios de heteroagressão (Apêndice1).

\subsection{Apresentação das variáveis}

\subsubsection{Variável dependente}

Estigma internalizado (escore total) - variável numérica; avaliada pela Escala de Avaliação do Estigma Internalizado ISMI-BR; maior pontuação nessa variável é indicativa de maior estigma internalizado

Alienação - variável numérica; subescalas da ISMI-BR; maior pontuação nessa variável é indicativa de maior alienação, que é um componente do estigma internalizado.

Aprovação do estereótipo: variável numérica; subescalas da ISMI-BR; maior pontuação nessa variável é indicativa de maior aprovação do estereótipo, que é um componente do estigma internalizado.

Percepção da discriminação: variável numérica; subescalas da ISMI-BR; maior pontuação nessa variável é indicativa de maior percepção da discriminação, que é um componente do estigma internalizado.

Evitação social: variável numérica; subescalas da ISMI-BR; maior pontuação nessa variável é indicativa de maior evitação social, que é um componente do estigma internalizado. Resistência ao estigma: variável numérica; subescalas da ISMI-BR; maior pontuação nessa variável é indicativa de maior resistência ao estigma internalizado.

\subsubsection{Variáveis independentes}

Sexo - variável qualitativa nominal (feminino; masculino);

Escolaridade - variável qualitativa ordinal, corresponde ao nível de escolaridade dos participantes (fundamental; médio; superior);

Estado civil - variável qualitativa nominal, corresponde à situação conjugal do participante (sem companheiro; com companheiro);

Trabalho - variável qualitativa nominal, discrimina se o paciente exerce atividade profissional no momento da coleta de dados (sim ou não);

Tarefas de casa - variável qualitativa nominal; considera se o participante auxilia nas tarefas de casa (sim ou não); 
Reside com - variável qualitativa nominal; considera se o participante reside sozinho ou não (Família; Amigos; Sozinho; Outros);

Diagnóstico - variável qualitativa nominal; corresponde ao diagnóstico médico do paciente (Transtorno Afetivo Bipolar e Depressão);

Conhecimento do diagnóstico - variável qualitativa nominal; considera se o participante sabe informar o diagnóstico médico compatível com o descrito no prontuário ( $\operatorname{sim}$ ou não);

Idade - variável numérica contínua (em anos);

Anos de tratamento - variável numérica contínua; considera há quanto tempo o participante faz tratamento psiquiátrico (em anos).

Esperança - variável numérica; maior pontuação nessa variável é indicativa de maior nível de esperança;

Adesão ao tratamento medicamentoso - variável analisada de duas formas: variável numérica (maior pontuação indica maior adesão) e variável qualitativa nominal (aderentes ou não aderentes);

Tentativas de suicídio - variável analisada de duas formas: numérica (número de tentativas prévias referido pelo paciente) e variável qualitativa nominal (com ou sem tentativas prévias), no modelo de regressão linear múltiplo;

Internações psiquiátricas - variável analisada de duas formas: numérica (número de internações psiquiátricas prévias referidas pelo paciente) e variável qualitativa nominal (com ou sem internações psiquiátricas prévias), no modelo de regressão linear múltiplo;

BPRS (pontuação total) - variável numérica; maiores pontuações são indicativas de maior gravidade de sintomas psiquiátricos;

Ansiedade psíquica - variável numérica; maiores pontuações nessa categoria são indicativos de maior nível de ansiedade;

Autodepreciação e sentimento de culpa - variável numérica; maiores pontuações são indicativas de maior nível de autodepreciação (menor autoestima) e sentimento de culpa;

Humor deprimido - variável numérica; maiores pontuações são indicativas de maior nível de tristeza, depressão, desânimo, desamparo e desesperança;

Afeto embotado ou inapropriado - variável numérica; maiores pontuações indicam menor capacidade ou motivação para sentir ou expressar as emoções;

Autoestima exagerada - variável numérica; maiores pontuações indicam maiores níveis de exagero da autoestima; 
Heteroagressão - variável qualitativa nominal; considera se o participante já apresentou episódios de heteroagressão ou violência direcionada a alguém (sim ou não).

\subsection{Análise dos dados}

Após a aplicação dos instrumentos, os dados foram codificados e duplamente digitados em uma base de dados estruturada no formato de planilha, no programa Excel e, em seguida, os possíveis erros de codificação ou de digitação foram verificados, comparados e corrigidos. Em seguida, os dados foram transportados e analisados no programa SPSS (Statistical Package for Social Science), versão 21.5 (PALLANT, 2010).

Foi utilizada estatística descritiva para a apresentação das variáveis demográficas, socioeconômicas, clínicas e relacionadas ao perfil farmacoterapêutico, estigma internalizado, e adesão ao tratamento. Posteriormente, foram aplicados testes de normalidade para direcionar a adoção de testes paramétricos ou não paramétricos. Para investigar possíveis associações entre o estigma internalizado e as variáveis qualitativas foram empregados os testes de comparação de médias, Teste T de Student, Kruskal-Wallis e Teste U de Mann-Whitney. O teste de correlação de Spearman foi empregado para investigar correlações entre o estigma internalizado e as variáveis numéricas. A análise da relação das variáveis de interesse com a variável estigma internalizado (escore total) foi realizada através do modelo de regressão linear múltiplo (MONTGOMERY, 2000). O nível de significância adotado em todos os testes foi de $\alpha=0,05$.

\subsection{Considerações éticas}

O estudo foi iniciado após autorização do Comitê de Ética em Pesquisa e seguiu as recomendações da Resolução $n^{\circ} 466 / 2012$, sobre pesquisas envolvendo seres humanos (BRASIL, 2012). Os participantes do estudo foram esclarecidos quanto ao anonimato, sigilo das informações e a liberdade para interromper a participação na pesquisa em caso de necessidade, sem que isso lhes acarretasse dano pessoal. A participação foi voluntária e sem fins lucrativos. Os participantes foram, ainda, esclarecidos sobre os objetivos do estudo e, também, que os dados obtidos seriam utilizados para a elaboração de trabalho científico e possível publicação. Foi mencionado, também, sobre os riscos relacionados ao tempo destinado à aplicação do questionário e à possibilidade de desconforto ao falar sobre o tema da investigação. Para minimizar tais questões, foi sugerido aos entrevistados que não se sentissem pressionados a falar sobre algum assunto que não quisessem abordar e caso houvesse desconforto, o entrevistado poderia optar entre evitar o assunto que gera desconforto ou ser ouvido. 
Após consentirem verbalmente em participar da pesquisa, foi solicitado aos participantes que assinassem o Termo de Consentimento Livre e Esclarecido (Apêndice 2). 


\section{RESULTADOS}

Participaram do estudo 108 pacientes provenientes do estado de São Paulo, a maioria do sexo feminino (75\%), na faixa etária dos 30 aos 60 anos (92\%), com média de idade de $50,8$ anos ( $\mathrm{DP}=13,0)$, mediana 53,0 (IQ=20) e cujo intervalo de idade foi de 23 a 82 anos (IC $95 \%=48,3-53,3)$. Quanto à escolaridade, os participantes com ensino fundamental completo/incompleto representam 39,8\%; médio incompleto/completo, 43,5\%; superior completo/ incompleto, 16,6\%. Com relação aos relacionamentos, disseram não ter companheiro $64,8 \%$; já $75,9 \%$ não trabalham, $76,9 \%$ auxiliam nas tarefas de casa e $87 \%$ residem com familiares, ou amigos (Tabela 1 ).

Ainda em relação às características socioeconômicas, parte dos participantes recebe algum auxílio financeiro do governo (benefício), 33,3\%, e uma menor parte é aposentada, $27,8 \%$.

Tabela 1. Caracterização sociodemográfica dos participantes do estudo ( $\mathrm{n}=108)$.

\begin{tabular}{lc}
\hline Variável & $\mathbf{N}(\%)$ \\
\hline Idade (anos) & $8(7,4)$ \\
$20-29$ & $19(17,6)$ \\
$30-39$ & $17(15,7)$ \\
$40-49$ & $37(34,3)$ \\
$50-59$ & $27(25)$ \\
$\geq 60$ & \\
Sexo & $81(75)$ \\
Feminino & $27(25)$ \\
Masculino & \\
Escolaridade & $30(27,8)$ \\
Fundamental incompleto & $13(12,0)$ \\
Fundamental completo & $11(10,2)$ \\
Médio incompleto & $36(33,3)$ \\
Médio completo & $9(8,3)$ \\
Superior incompleto & $9(8,3)$ \\
Superior completo & \\
Estado civil & $25(23,1)$ \\
Solteiro & $11(10,2)$ \\
Viúvo & $34(31,5)$ \\
Separado/ divorcio & $38(35,2)$ \\
Casado/ companheiro fixo & \\
Trabalho & $82(75,9)$ \\
Não & $26(24,1)$ \\
Sim & \\
Auxilia nas tarefas de casa & $25(23,1)$ \\
Não & $83(76,9)$ \\
Sim & \\
Reside com & $94(87,0)$ \\
Família/ amigos & $14(13,0)$ \\
Sozinho & \\
\hline
\end{tabular}

Fonte: elaborado pela autora (2017) 
Entre os participantes, 53,7\% têm como diagnóstico principal Transtorno Afetivo Bipolar (TAB), 71,3\% recebeu o diagnóstico e iniciou tratamento medicamentoso $(72,2 \%)$ quanto tinha entre 20 e 49 anos. Nessa mesma faixa etária se concentrou o maior número de primeiras internações (37,9\%); já as últimas internações concentraram-se dos 30 aos 59 anos $(36,1 \%)$. A maioria dos pacientes tinha conhecimento do diagnóstico (85,2\%), fazia tratamento há no máximo nove anos $(68,5 \%)$, teve uma ou mais internações psiquiátricas $(54,6 \%)$, uma ou mais tentativas de suicídio $(54,6 \%)$ e afirmou nunca ter apresentado episódios de heteroagressão $(52,8 \%)$ (Tabela 2). Foi considerada aderente ao tratamento $74,1 \%$ dos entrevistados. A esperança foi medida por meio de uma escala cuja pontuação varia de 12 a 48. A média obtida para essa variável foi de 31,2 (DP=6,7), mediana 31,0 $(I Q=9)$ e o intervalo de escore obtido foi entre $14-48$ (IC 95\%=29,9 - 32,5) (Tabela 2).

Tabela 2. Distribuição dos participantes segundo aspectos clínicos, adesão e esperança (n=108).

\begin{tabular}{|c|c|c|c|c|c|}
\hline Variável & $\mathbf{N}(\%)$ & Média (DP) & $\begin{array}{l}\text { Mediana } \\
\text { (IQ) }\end{array}$ & $\begin{array}{c}\text { Intervalo } \\
\text { obtido }\end{array}$ & IC $95 \%$ \\
\hline \multicolumn{6}{|l|}{ Diagnóstico } \\
\hline Transtorno bipolar & $58(53,7)$ & & & & \\
\hline Depressão & $50(46,3)$ & & & & \\
\hline $\begin{array}{l}\text { Anos de } \\
\text { tratamento }\end{array}$ & & $7,3(5,1)$ & $6,0(7)$ & $1-20$ & $6,4-8,3$ \\
\hline $0-9$ & $74(68,5)$ & & & & \\
\hline $10-19$ & $29(26,9)$ & & & & \\
\hline$\geq 20$ & $5(4,6)$ & & & & \\
\hline \multicolumn{6}{|l|}{$\begin{array}{l}\text { Conhecimento } \\
\text { sobre diagnóstico }\end{array}$} \\
\hline Não & $16(14,8)$ & & & & \\
\hline Sim & $92(85,2)$ & & & & \\
\hline $\begin{array}{l}\text { Internações } \\
\text { psiquiátricas }\end{array}$ & & $1,9(2,8)$ & $1,0(3)$ & $0-12$ & $1,4-2,4$ \\
\hline 0 & $50(46,3)$ & & & & \\
\hline 1 & $16(14,8)$ & & & & \\
\hline 2 & $13(12,0)$ & & & & \\
\hline 3 ou mais & $29(26,9)$ & & & & \\
\hline Tentativas suicídio & & $1,6(2,5)$ & $1,0(2)$ & $0-10$ & $1,2-2,1$ \\
\hline 0 & $49(45,4)$ & & & & \\
\hline 1 & $23(21,3)$ & & & & \\
\hline 2 & $15(13,9)$ & & & & \\
\hline 3 ou mais & $21(19,4)$ & & & & \\
\hline \multicolumn{6}{|l|}{ Já agrediu alguém } \\
\hline Não & $57(52,8)$ & & & & \\
\hline Sim & $51(47,2)$ & & & & \\
\hline \multicolumn{6}{|l|}{ Adesão } \\
\hline Não & $28(25,9)$ & $5,3(0,8)$ & $5,6(10)$ & $2,1-6,0$ & $64,8-82,0$ \\
\hline Sim & $80(74,1)$ & - & - & - & - \\
\hline \multicolumn{5}{|l|}{ Esperança } & $29,9-32,5$ \\
\hline
\end{tabular}

Fonte: elaborado pela autora (2017) 
O estigma internalizado foi avaliado pela ISMI, cujo escore total pode variar de 29 a 116. Entre os participantes do estudo, a pontuação variou de 41 a 108 (IC 95\%=72,5-78,2) e obteve-se média de 75,4. Dentre as subcategorias da escala, a menor pontuação obtida foi em "Percepção da discriminação" (média=13,5) e a maior foi identificada em "Alienação" (média=17,1) (Tabela 3).

Tabela 3. Escores obtidos na escala Estigma Internalizado - ISMI-BR e suas subcategorias ( $\mathrm{n}=108$ ).

\begin{tabular}{lcccc}
\hline \multicolumn{1}{c}{ Variáveis } & Média (DP) & $\begin{array}{c}\text { Mediana } \\
(\text { IQ) }\end{array}$ & $\begin{array}{c}\text { Intervalo } \\
\text { obtido }\end{array}$ & IC 95\% \\
\hline Autoestigma - escore total & $75,4(15,0)$ & $75,5(23)$ & $41-108$ & $72,5-78,2$ \\
Alienação & $17,1(4,0)$ & $18,0(6)$ & $7-24$ & $16,3-17,8$ \\
Aprovação do estereótipo & $16,6(3,8)$ & $16,0(5)$ & $8-27$ & $15,9-17,4$ \\
Percepção da discriminação & $13,5(3,4)$ & $14,0(5)$ & $6-20$ & $12,9-14,1$ \\
Evitação social & $16,2(4,4)$ & $16,5(6)$ & $6-24$ & $15,4-17,1$ \\
Resistência ao estigma & $11,9(2,7)$ & $12,0(4)$ & $5-19$ & $11,4-12,4$ \\
\hline
\end{tabular}

Fonte: elaborado pela autora (2017)

No que se refere à sintomatologia dos participantes, avaliada pela BPRS, foi identificada pontuação grave apenas em "autoestima exagerada", em um participante $(0,9 \%)$. Os sintomas que receberam pontuação moderada em alguns casos foram: "humor deprimido" $(16,7 \%)$; "retraimento emocional" (1,9\%); "auto estima exagerada" $(0,9 \%)$; "hostilidade" $(0,9 \%)$ e "conteúdo do pensamento incomum" (0,9\%). Os sintomas avaliados e classificados como ausentes, em maior quantidade, foram: "hostilidade" (93,5\%); "preocupações somáticas" (95,4\%); “desorganização conceitual” (95,4\%); “falta de cooperação" (96,3\%); "alucinações" (97,2\%); "agitação psicomotora" (97,2\%); "retardo psicomotor" (98,1\%); “desconfiança" (99,1\%); "conteúdo do pensamento incomum" (99,1\%); "desorientação e confusão" (99,1\%) e "distúrbios motores específicos" (100\%) (Tabela 4).

Tabela 4. Distribuição dos participantes do estudo segundo a variável BPRS-a (n=108).

\begin{tabular}{lccccc}
\hline Variável & $\begin{array}{c}\text { Ausente } \\
\mathbf{N}(\%)\end{array}$ & $\begin{array}{c}\text { Muito leve } \\
\mathbf{N}(\%)\end{array}$ & $\begin{array}{c}\text { Leve } \\
\mathbf{N}(\%)\end{array}$ & $\begin{array}{c}\text { Moderado } \\
\mathbf{N}(\%)\end{array}$ & $\begin{array}{c}\text { Grave/ } \\
\text { extremo } \\
\text { N (\%) }\end{array}$ \\
\hline $\begin{array}{l}\text { Preocupações } \\
\text { somáticas }\end{array}$ & $103(95,4)$ & $3(2,8)$ & $2(1,9)$ & - & - \\
$\begin{array}{l}\text { Ansiedade psíquica } \\
\text { Retraimento } \\
\text { emocional }\end{array}$ & $49(45,4)$ & $38(35,2)$ & $21(19,4)$ & - & - \\
$\begin{array}{l}\text { Desorganização } \\
\text { conceitual } \\
\text { incoerência) }\end{array}$ & $76(70,4)$ & $16(14,8)$ & $14(13,0)$ & $2(1,9)$ & - \\
$\begin{array}{l}\text { Autodepreciação e } \\
\text { sentimento de culpa } \\
\text { Ansiedade }\end{array}$ & $103(95,4)$ & $4(3,7)$ & $1(0,9)$ & - & - \\
& $42(38,9)$ & $41(38,0)$ & $25(23,1)$ & - & - \\
\end{tabular}




\begin{tabular}{|c|c|c|c|c|c|}
\hline Variável & $\begin{array}{l}\text { Ausente } \\
\mathbf{N}(\%)\end{array}$ & $\begin{array}{l}\text { Muito leve } \\
\text { N (\%) }\end{array}$ & $\begin{array}{l}\text { Leve } \\
\mathbf{N}(\%)\end{array}$ & $\begin{array}{l}\text { Moderado } \\
\text { N (\%) }\end{array}$ & $\begin{array}{c}\text { Grave/ } \\
\text { extremo } \\
\mathbf{N}(\%)\end{array}$ \\
\hline $\begin{array}{l}\text { Distúrbios motores } \\
\text { específicos }\end{array}$ & $108(100)$ & - & - & - & - \\
\hline Autoestima exagerada & $85(78,7)$ & $10(9,3)$ & $11(10,2)$ & $1(0,9)$ & $1(0,9)$ \\
\hline Humor deprimido & $30(27,8)$ & $29(26,9)$ & $31(28,7)$ & $18(16,7)$ & \\
\hline Hostilidade & $101(93,5)$ & $5(4,6)$ & $1(0,9)$ & $1(0,9)$ & - \\
\hline Desconfiança & $107(99,1)$ & $1(0,9)$ & - & - & - \\
\hline Alucinações & $105(97,2)$ & $2(1,9)$ & $1(0,9)$ & - & - \\
\hline Retardo psicomotor & $106(98,1)$ & $2(1,9)$ & - & - & - \\
\hline Falta de cooperação & $104(96,3)$ & $3(2,8)$ & $1(0,9)$ & - & - \\
\hline $\begin{array}{l}\text { Conteúdo do } \\
\text { pensamento incomum }\end{array}$ & $107(99,1)$ & - & - & $1(0,9)$ & - \\
\hline $\begin{array}{l}\text { Afeto embotado ou } \\
\text { inapropriado }\end{array}$ & $59(54,6)$ & $44(40,7)$ & $5(4,6)$ & - & - \\
\hline Agitação psicomotora & $105(97,2)$ & $2(1,9)$ & $1(0,9)$ & - & - \\
\hline $\begin{array}{l}\text { Desorientação e } \\
\text { confusão }\end{array}$ & $107(99,1)$ & $1(0,9)$ & - & - & - \\
\hline \multirow{2}{*}{\multicolumn{2}{|c|}{ Escore Total BPRS }} & Média (DP) & $\begin{array}{l}\text { Mediana } \\
\text { (IQ) }\end{array}$ & $\begin{array}{l}\text { Intervalo } \\
\text { obtido }\end{array}$ & IC $95 \%$ \\
\hline & & $5,03(2,3)$ & $5,0(4)$ & $1-11$ & $4,58-5,47$ \\
\hline
\end{tabular}

Fonte: elaborado pela autora (2017)

Foram utilizados testes de comparação de médias para avaliar associações entre as variáveis sociodemográficas e clínicas do estudo, esperança e adesão (classificação dicotômica) com as subescalas do instrumento Escala de Avaliação do Estigma Internalizado ISMI-BR.

Pessoas que não trabalhavam tiveram maiores escores nas subescalas: "alienação", "aprovação do estereótipo", "percepção da discriminação" e "evitação social". Pessoas que referiram já ter agredido alguém tiveram maior pontuação na subescala "aprovação do estereótipo".

Os participantes do estudo classificados como não aderentes, na aplicação da escala MAT tiveram maiores escores nas subescalas: "alienação", "aprovação do estereótipo" e “percepção da discriminação" (Tabela 5). 
Tabela 5. Distribuição dos participantes segundo os testes de comparação de médias entre as variáveis e as subcategorias da Escala de Avaliação do Estigma Internalizado ISMI-BR $(\mathrm{n}=108)$.

\begin{tabular}{|c|c|c|c|c|c|c|c|c|c|c|}
\hline \multirow[t]{2}{*}{ Variáveis } & \multicolumn{2}{|c|}{ Alienação } & \multicolumn{2}{|c|}{ Aprovação do estereótipo } & \multicolumn{2}{|c|}{$\begin{array}{l}\text { Percepção da } \\
\text { discriminação }\end{array}$} & \multicolumn{2}{|c|}{ Evitação social } & \multicolumn{2}{|c|}{ Resistência ao estigma } \\
\hline & Média (ED) & p-valor & Média (ED) & p-valor & Média (ED) & p-valor & Média (ED) & p-valor & Média (ED) & p-valor \\
\hline Sexo & & $0,390^{* *}$ & & $0,193^{* *}$ & & $0,498^{* *}$ & & $0,481 * *$ & & $0,816^{* *}$ \\
\hline Feminino & $17,3(4,0)$ & & $17,0(3,8)$ & & $13,6(3,6)$ & & $16,4(4,4)$ & & $11,9(2,7)$ & \\
\hline Masculino & $16,4(3,7)$ & & $15,6(3,5)$ & & $13,1(2,5)$ & & $15,6(4,3)$ & & $11,8(2,6)$ & \\
\hline Escolaridade & & $0,120^{*}$ & & $0,062 *$ & & $0,334 *$ & & $0,122 *$ & & $0,757^{*}$ \\
\hline Fundamental & $18,0(3,6)$ & & $17,5(3,0)$ & & $14,1(3,1)$ & & $17,3(4,0)$ & & $12,0(2,3)$ & \\
\hline Médio & $16,6(4,0)$ & & $16,4(4,1)$ & & $13,2(3,5)$ & & $15,5(4,5)$ & & $11,6(3,0)$ & \\
\hline Superior & $16,1(4,4)$ & & $15,2(4,3)$ & & $12,9(3,8)$ & & $15,4(4,6)$ & & $12,3(2,8)$ & \\
\hline Estado civil & & $0,105^{* *}$ & & $0,271 * * *$ & & $0,443 * *$ & & $0,392 * *$ & & $0,437 * *$ \\
\hline Sem companheiro & $16,6(4,0)$ & & $16,3(3,7)$ & & $13,3(3,4)$ & & $15,9(4,4)$ & & $12,0(2,6)$ & \\
\hline Com companheiro & $18,0(3,8)$ & & $17,2(4,0)$ & & $13,8(3,3)$ & & $16,9(4,3)$ & & $11,8(2,8)$ & \\
\hline Trabalho & & $<0,001 * *$ & & $<0,001 * *$ & & $<0,001 * *$ & & $<0,001 * *$ & & $0,197 * *$ \\
\hline Não & $18,0(3,7)$ & & $17,6(3,5)$ & & $14,2(3,3)$ & & $17,2(4,1)$ & & $12,1(2,8)$ & \\
\hline Sim & $14,2(3,3)$ & & $13,7(3,3)$ & & $11,3(2,8)$ & & $13,2(3,9)$ & & $11,2(2,4)$ & \\
\hline $\begin{array}{l}\text { Auxilia nas } \\
\text { tarefas de casa }\end{array}$ & & $0,682^{* *}$ & & $0,590 * * *$ & & $0,701 * *$ & & $0,530 * *$ & & $0,383^{* *}$ \\
\hline Não & $16,8(3,9)$ & & $16,3(3,4)$ & & $13,3(2,9)$ & & $15,6(4,4)$ & & $12,3(2,9)$ & \\
\hline Sim & $17,2(4,0)$ & & $16,7(3,9)$ & & $13,6(3,5)$ & & $16,4(4,4)$ & & $11,8(2,6)$ & \\
\hline
\end{tabular}




\begin{tabular}{|c|c|c|c|c|c|c|c|c|c|c|}
\hline \multirow{2}{*}{$\begin{array}{l}\text { Variáveis } \\
\text { Reside com }\end{array}$} & \multicolumn{2}{|c|}{ Alienação } & \multicolumn{2}{|c|}{ Aprovação do estereótipo } & \multicolumn{2}{|c|}{$\begin{array}{l}\text { Percepção da } \\
\text { discriminação }\end{array}$} & \multicolumn{2}{|c|}{ Evitação social } & \multicolumn{2}{|c|}{ Resistência ao estigma } \\
\hline & & $0,772 * *$ & & $0,409 * * *$ & & $0,836^{* *}$ & & $0,640^{* *}$ & & $0,229 * *$ \\
\hline Família/Amigos & $17,0(4,0)$ & & $16,8(3,8)$ & & $13,5(3,3)$ & & $16,1(4,4)$ & & $11,8(2,8)$ & \\
\hline Sozinho & $17,4(3,7)$ & & $15,9(3,4)$ & & $13,2(4,1)$ & & $16,9(4,1)$ & & $12,6(2,1)$ & \\
\hline Diagnóstico & & $0,724 * *$ & & $0,386 * *$ & & $0,261 * *$ & & $0,831 * *$ & & $0,832 * *$ \\
\hline $\begin{array}{l}\text { Transtorno Afetivo } \\
\text { Bipolar-TAB }\end{array}$ & $17,2(4,0)$ & & $16,7(3,9)$ & & $13,8(3,4)$ & & $16,1(4,5)$ & & $11,9(2,8)$ & \\
\hline Depressão & $16,9(3,9)$ & & $16,6(3,6)$ & & $13,2(3,4)$ & & $16,4(4,4)$ & & $11,9(2,6)$ & \\
\hline $\begin{array}{l}\text { Conhecimento } \\
\text { sobre diagnóstico }\end{array}$ & & $0,355^{* *}$ & & $0,164^{* *}$ & & $0,062 * *$ & & $0,383 * *$ & & $0,684 * *$ \\
\hline Não & $18,2(3,1)$ & & $17,7(3,1)$ & & $14,9(3,0)$ & & $17,3(3,9)$ & & $11,8(2,3)$ & \\
\hline Sim & $16,9(4,1)$ & & $16,5(3,9)$ & & $13,3(3,4)$ & & $16,0(4,5)$ & & $11,9(2,8)$ & \\
\hline Já agrediu alguém & & $0,162 * *$ & & $0,006^{* *}$ & & $0,054 * *$ & & $0,067 * *$ & & $0,112 * *$ \\
\hline Não & $16,6(4,0)$ & & $15,7(3,5)$ & & $12,9(3,3)$ & & $15,5(4,2)$ & & $11,5(2,6)$ & \\
\hline Sim & $17,7(3,8)$ & & $17,6(3,8)$ & & $14,1(3,4)$ & & $17,0(4,5)$ & & $12,3(2,8)$ & \\
\hline Adesão $* * * *$ & & $0,023 * *$ & & $0,028 * *$ & & $0,008 * *$ & & $0,123 * *$ & & $0,411 * *$ \\
\hline Não aderente & $18,4(4,0)$ & & $17,9(4,5)$ & & $14,8(3,9)$ & & $17,1(5,1)$ & & $12,4(3,0)$ & \\
\hline Aderente & $16,6(3,9)$ & & $16,2(3,4)$ & & $13,1(3,1)$ & & $15,9(4,1)$ & & $11,7(2,6)$ & \\
\hline
\end{tabular}

${ }^{*}$ Kruskal-Wallis; ${ }^{* *}$ Teste U de Mann-Whitney; ${ }^{* * *}$ Teste t para igualdade de médias **** Resultados dicotômico da escala MAT

Fonte: elaborado pela autora (2017) 
Nos testes de correlação foi identificado que quanto maior o número de internações psiquiátricas, maiores as pontuações nas subescalas: "alienação", "aprovação do estereótipo", "percepção da discriminação" e "evitação social".

A menor adesão ao tratamento medicamentoso correlacionou-se com a maior pontuação nas subescalas: "alienação", "aprovação do estereótipo", "percepção da discriminação" e "evitação social".

Um maior o número de tentativas de suicídio, maior escore total da BPRS (indicativo de maior sintomatologia) e a menor pontuação na escala de esperança estiveram correlacionados com maiores pontuações em todas as subescalas de estigma internalizado.

Maiores pontuações nos sintomas "autodepreciação e sentimento de culpa" e "humor deprimido" também estiveram associados a maiores pontuações em todas as cinco subescalas. Maior pontuação no sintoma "afeto embotado ou inapropriado" correlacionou-se com maiores escores nas subescalas: "alienação", "aprovação do estereótipo", "percepção da discriminação" e "evitação social”. Já a sintomatologia mais grave em "autoestima exagerada" esteve inversamente correlacionada à alienação, aprovação do estereótipo, evitação social e resistência ao estigma (Tabela 6). 
Tabela 6. Distribuição dos participantes do estudo segundo a correlação entre as subcategorias da Escala de Avaliação do Estigma Internalizado ISMI-BR com as demais variáveis $(\mathrm{n}=108)$.

\begin{tabular}{|c|c|c|c|c|c|c|c|c|c|c|}
\hline \multirow[t]{2}{*}{ Variáveis } & \multicolumn{2}{|c|}{ Alienação } & \multicolumn{2}{|c|}{ Aprovação do estereótipo } & \multicolumn{2}{|c|}{$\begin{array}{l}\text { Percepção da } \\
\text { discriminação }\end{array}$} & \multicolumn{2}{|c|}{ Evitação social } & \multicolumn{2}{|c|}{ Resistência ao estigma } \\
\hline & $\mathbf{C}$ & p-valor & $\mathbf{C}$ & p-valor & $\mathbf{C}$ & p-valor & $\mathbf{C}$ & p-valor & $\mathbf{C}$ & p-valor \\
\hline Idade & 0,053 & 0,585 & 0,144 & 0,239 & 0,053 & 0,586 & 0,089 & 0,361 & $-0,060$ & 0,537 \\
\hline $\begin{array}{l}\text { Anos de } \\
\text { tratamento }\end{array}$ & 0,128 & 0,187 & 0,163 & 0,091 & 0,150 & 0,121 & 0,132 & 0,175 & 0,024 & 0,805 \\
\hline $\begin{array}{l}\text { Internações } \\
\text { psiquiátricas }\end{array}$ & 0,291 & 0,002 & 0,238 & 0,013 & 0,370 & $<0,001$ & 0,263 & 0,006 & 0,059 & 0,545 \\
\hline $\begin{array}{l}\text { Tentativas } \\
\text { suicídio }\end{array}$ & 0,352 & $<0,001$ & 0,370 & $<0,001$ & 0,344 & $<0,001$ & 0,390 & $<0,001$ & 0,246 & 0,010 \\
\hline $\begin{array}{l}\text { Adesão ao } \\
\text { tratamento* }\end{array}$ & $-0,345$ & $<0,001$ & $-0,226$ & 0,019 & $-0,305$ & $<0,001$ & $-0,276$ & 0,004 & $-0,077$ & 0,429 \\
\hline Esperança & $-0,625$ & $<0,001$ & $-0,558$ & $<0,001$ & $-0,397$ & $<0,001$ & $-0,572$ & $<0,001$ & $-0,480$ & $<0,001$ \\
\hline $\begin{array}{l}\text { BPRS escore } \\
\text { total }\end{array}$ & 0,434 & $<0,001$ & 0,371 & $<0,001$ & 0,394 & $<0,001$ & 0,401 & $<0,001$ & 0,262 & 0,006 \\
\hline $\begin{array}{l}\text { Ansiedade } \\
\text { psíquica }\end{array}$ & 0,133 & 0,170 & 0,096 & 0,321 & 0,159 & 0,100 & 0,028 & 0,778 & 0,071 & 0,467 \\
\hline $\begin{array}{l}\text { Auto } \\
\text { depreciação e } \\
\text { sentimento de } \\
\text { culpa }\end{array}$ & 0,361 & $<0,001$ & 0,300 & 0,002 & 0,252 & 0,009 & 0,352 & $<0,001$ & 0,253 & 0,008 \\
\hline $\begin{array}{l}\text { Humor } \\
\text { deprimido }\end{array}$ & 0,503 & $<0,001$ & 0,356 & $<0,001$ & 0,351 & $<0,001$ & 0,445 & $<0,001$ & 0,359 & $<0,001$ \\
\hline
\end{tabular}




\begin{tabular}{lccccccccc}
\hline Variáveis & \multicolumn{2}{c}{ Alienação } & Aprovação do estereótipo & $\begin{array}{l}\text { Percepção da } \\
\text { discriminação }\end{array}$ & Evitação social & Resistência ao estigma \\
\hline $\begin{array}{l}\text { Afeto } \\
\text { embotado ou } \\
\text { inapropriado }\end{array}$ & 0,253 & 0,008 & 0,235 & 0,014 & 0,330 & $<0,001$ & 0,334 & $<0,001$ & 0,061 \\
$\begin{array}{l}\text { Auto estima } \\
\text { exagerada }\end{array}$ & $-0,258$ & 0,007 & $-0,271$ & 0,005 & $-0,088$ & 0,364 & $-0,244$ & 0,011 & $-0,328$ \\
\hline
\end{tabular}

*Resultados numéricos da escala MAT

Fonte: elaborado pela autora (2017) 
Ao comparar as médias das variáveis categóricas do estudo com o estigma internalizado foram encontradas associações significativas nas variáveis "trabalho", "adesão" (resultados dicotômicos) e "histórico prévio de heteroagressão". Assim, observou-se que pessoas que não trabalhavam, que já haviam agredido alguém e que foram classificadas como não aderentes ao tratamento medicamentoso tiveram maiores médias no escore total da Escala de Avaliação do Estigma Internalizado ISMI-BR (Tabela 7).

Tabela 7. Distribuição dos participantes do estudo segundo a comparação de médias entre estigma internalizado e as variáveis sociodemográficas e clínicas (n=108).

\begin{tabular}{|c|c|c|}
\hline \multirow[t]{2}{*}{ Variáveis } & \multicolumn{2}{|c|}{ Estigma Internalizado } \\
\hline & Média (ED) & p-valor \\
\hline Sexo & & $0,279 * *$ \\
\hline Feminino & $76,3(15,1)$ & \\
\hline Masculino & $72,5(14,5)$ & \\
\hline Escolaridade & & $0,107 *$ \\
\hline Fundamental & $79,0(12,1)$ & \\
\hline Médio & $73,3(16,0)$ & \\
\hline Superior & $72,0(17,0)$ & \\
\hline Estado civil & & $0,271 * *$ \\
\hline Sem companheiro & $74,1(14,8)$ & \\
\hline Com companheiro & $77,7(15,2)$ & \\
\hline Trabalho & & $<0,001 * * *$ \\
\hline Não & $79,1(13,7)$ & \\
\hline Sim & $63,5(12,7)$ & \\
\hline Auxilia nas tarefas de casa & & $0,685^{* * *}$ \\
\hline Não & $74,3(15,1)$ & \\
\hline Sim & $75,7(15,0)$ & \\
\hline Reside com & & $0,893 * * *$ \\
\hline Família/Amigos & $75,3(14,9)$ & \\
\hline Sozinho & $75,9(16,1)$ & \\
\hline Diagnóstico & & $0,753 * * *$ \\
\hline Transtorno Afetivo Bipolar - TAB & $75,8(15,5)$ & \\
\hline Depressão & $74,9(14,4)$ & \\
\hline
\end{tabular}




\begin{tabular}{lcc}
\hline Variáveis & \multicolumn{2}{c}{ Estigma Internalizado } \\
\hline Conhecimento sobre diagnóstico & $0,191 * * *$ \\
Não & $79,9(11,1)$ & \\
Sim & $74,6(15,4)$ & $0,024 * * *$ \\
Já agrediu alguém & $72,3(14,4)$ & \\
Não & $78,8(15,0)$ & $0,016 * *$ \\
Sim & & \\
Adesão**** & $80,6(16,7)$ & \\
Não aderente & $73,5(13,9)$ & \\
Aderente & & \\
*ANOVA; ** Teste U de Mann-Whitney; *** Teste de amostras independentes (teste t para igualdade
\end{tabular}
de médias); **** Resultados dicotômicos da escala MAT.

Fonte: elaborado pela autora (2017)

Uma maior quantidade de internações psiquiátricas, maior quantidade de tentativas de suicídio e maiores pontuações no escore total da BPRS estiveram associadas à maior pontuação na Escala de Avaliação de Estigma Internalizado ISMI-BR, assim como maiores pontuações nos sintomas: "autodepreciação e sentimento de culpa", "humor deprimido" e "afeto embotado ou inapropriado".

Houve correlação negativa entre as variáveis "autoestima exagerada", "adesão" e “esperança” com a pontuação atingida na ISMI-BR (Tabela 8).

Tabela 8. Distribuição dos participantes do estudo segundo a correlação entre estigma internalizado e as variáveis sociodemográficas e clínicas $(\mathrm{n}=108)$.

\begin{tabular}{lcc}
\hline Variáveis & \multicolumn{2}{c}{ Estigma Internalizado } \\
\hline & $\mathbf{C}$ & p-valor \\
\cline { 2 - 3 } Idade & 0,066 & 0,499 \\
Anos de tratamento & 0,147 & 0,129 \\
Internações psiquiátricas & 0,310 & 0,001 \\
Tentativas suicídio & 0,433 & $<0,001$ \\
Adesão ao tratamento * & $-0,315$ & 0,001 \\
Esperança & $-0,653$ & $<0,001$ \\
BPRS escore total & 0,447 & $<0,001$
\end{tabular}




\begin{tabular}{lcc}
\hline Variáveis & Estigma Internalizado & \\
\hline Ansiedade psíquica & 0,107 & 0,270 \\
Auto depreciação e sentimento de culpa & 0,377 & $<0,001$ \\
Humor deprimido & 0,495 & $<0,001$ \\
Afeto embotado ou inapropriado & 0,313 & 0,001 \\
Autoestima exagerada & $-0,283$ & 0,003 \\
\hline
\end{tabular}

* Resultados numéricos da escala MAT

Fonte: elaborado pela autora (2017)

Foi utilizado o Modelo de Regressão Linear Múltiplo, tendo como desfecho o escore total da ISMI, no qual maiores pontuações são indicativas de maior estigma internalizado. $\mathrm{O}$ modelo como um todo foi capaz de explicar $56,1 \%$ da variância. Ter profissão foi um preditor de menor pontuação na ISMI $(-5,93$; IC95\%=11,1 - -0,8) e o histórico de tentativa prévia de suicídio foi preditor de maior pontuação $(5,15$; IC95\%=1,0 - 9,3). A elevação de um ponto no escore total da BPRS aumentou em aproximadamente um ponto o escore da ISMI $(1,16$; IC95\%=0,2 - 2,1) e o aumento de ponto na Escala de avaliação da esperança reduziu o escore atingido pelo paciente na ISMI em aproximadamente um ponto $(-1,11 ;$ IC95\%=-1,5 - -0,8) (Tabela 9).

Tabela 9. Distribuição dos participantes do estudo segundo o modelo de regressão linear múltiplo variável dependente: Estigma internalizado $(\mathrm{n}=108)$.

\begin{tabular}{lcccc}
\hline Variáveis não dependentes & Estimativa & Erro padrão & p-valor & IC 95\% \\
\hline Trabalho (sim - não) & $-5,93$ & 2,59 & 0,02 & $-11,1--0,8$ \\
Agressão (sim - não) & $-1,78$ & 2,21 & 0,42 & $-6,2-2,6$ \\
Adesão (sim - não) & $-0,16$ & 2,46 & 0,95 & $-5,0-4,7$ \\
Internação Psiquiátrica (sim - não) & 3,85 & 2,23 & 0,09 & $0,6-8,3$ \\
Tentativa de Suicídio (sim - não) & 5,15 & 2,08 & 0,02 & $1,0-9,3$ \\
BPRS_total & 1,16 & 0,47 & 0,02 & $0,2-2,1$ \\
Esperança & $-1,11$ & 0,17 & $<0,01$ & $-1,5--0,8$ \\
\hline
\end{tabular}

Fonte: elaborado pela autora (2017) 


\section{DISCUSSÃO}

A literatura sobre o estigma internalizado, avaliado por meio da escala ISMI, inclui diferentes populações, tais como pacientes com transtornos mentais em geral (ASRAT, AYENALÉM, YIMER, 2018; OCISKOVÁ et al., 2014; GIRMA et al., 2013), transtornos psicóticos (OLÇUN; ALTUN, 2017; LI et al., 2018), transtornos de ansiedade (OCISKOVÁ et al., 2018; CINCULOVA et al, 2017) e transtornos relacionados ao uso de substâncias (SARKAR et al., 2017), mas existem poucos estudos sobre o estigma internalizado entre pessoas com transtornos de humor. Uma pesquisa realizada em 13 países europeus com 1182 participantes com diagnóstico de depressão ou transtorno afetivo bipolar encontrou que $1 / 5$ dos participantes experimentava níveis moderados a altos de estigma internalizado (BROHAN et al., 2010). Outro estudo realizado em Portugal com 261 participantes diagnosticados com esquizofrenia e transtornos do humor apontou que o estigma internalizado era problema igualmente importante para pessoas com esses dois diagnósticos (OLIVEIRA et al., 2015b). Na literatura não foram encontrados estudos que abordam, em conjunto, adesão, sintomatologia, esperança, estigma internalizado, heteroagressão e histórico de tentativas de suicídio. Por isso, este trabalho traz grandes contribuições nessa área de conhecimento.

No presente estudo predominaram mulheres adultas, sem companheiro, sem trabalho, com ensino fundamental ou médio incompleto/completo e que residia com familiares, ou amigos. A única variável sociodemográfica associada ao estigma internalizado foi a variável trabalho. Em estudos realizados com pacientes com transtornos psicóticos, depressão e TOC em Singapura e na Espanha, não foram encontradas associações entre variáveis sociodemográficas e estigma internalizado (PICCO et al., 2016; TOURINO et al., 2018). O estudo transversal já mencionado, realizado em 13 países europeus com 1182 pacientes diagnosticados com transtorno de humor, indicou que educação universitária e emprego estiveram associados a menores níveis de estigma internalizado (BROHAN et al., 2010), e um estudo português realizado com pessoas com esquizofrenia e transtornos de humor descobriu que o estigma esteve relacionado com a perda de emprego, falta de oportunidade em constituir família e diminuição do suporte social (OLIVEIRA et al., 2015b).

Neste estudo, pessoas que disseram não trabalhar tiveram mais estigma internalizado. Tal associação também foi encontrada previamente em uma pesquisa desenvolvida com pessoas com transtornos psicóticos e transtornos de ansiedade afetiva (KALISOVA, 2018). Uma possível explicação para essa associação é que o trabalho propicia interação social e inclusão (KRAJEWSKI et al., 2013; YANOS et al., 2012) e representa uma adequação do 
indivíduo às exigências e padrões estabelecidos pela sociedade, enquanto a falta de trabalho pode estar ligada à inadequação e exclusão (CORRIGAN; WASSEL, 2008). Além disso, é importante considerar que o estigma pode prejudicar a integração social, reduzir oportunidades de trabalho, independência financeira e maior direcionamento e controle da própria vida (CORRIGAN; WASSEL, 2008; KALISOVA, 2018).

A maior parte da amostra deste estudo tinha diagnóstico de $\mathrm{TAB}$, tinha conhecimento do diagnóstico, e o recebeu diagnóstico na faixa etária dos 20 a 49 anos, período associado à produtividade, mudanças, cobranças relacionadas a padrões sociais e formação de laços familiares (KALISOVA, 2018).

No estudo, maiores pontuações na BPRS, indicativas de sintomas mais graves, estiveram associadas a um maior nível de estigma internalizado, sendo que a elevação de um ponto no escore total da BPRS aumentou em aproximadamente um ponto o escore da ISMI. A literatura sugere que o estigma internalizado relacionado aos transtornos mentais pode ser mais intenso em casos de sintomas mais agudos ou severos (OLIVEIRA et al., 2015; OEXLE et al., 2018; LIVINGSTON, 2010), embora não haja consenso a esse respeito, visto que o estudo realizado com 186 participantes com depressão maníaca não encontrou relação entre sintomas de humor e estigma (HAYWARD et al., 2002).

Neste estudo, maiores pontuações nos sintomas "autodepreciação e sentimento de culpa" e "humor deprimido" associaram-se à maior pontuação no escore total da ISMI-BR e nas cinco subescalas que a compõem. A associação encontrada entre sintomas depressivos e estigma internalizado pode estar relacionada à maior percepção sobre a própria condição clínica, bem como a características dos sintomas depressivos que incluem autodepreciação, desesperança e pessimismo (MACDOUGALL; VANDERMEER; NORMAN, 2015). É possível que tais sintomas e o estigma se reforcem mutuamente, pois o estigma também pode potencializar sintomas depressivos, desesperança e um pior funcionamento do indivíduo (VYAVAHARKAR et al., 2010; CERIT et al., 2012; BERRY; GREENWOLD, 2017), além de culpa pela sua condição psíquica, menor autoeficácia, autoestima e falta de empoderamento no controle da própria vida (HANAFIAH; BORTEL, 2015; LIVINGSTON; BOYD, 2010; KALISOVA et al., 2018).

Os sintomas de autoestima exagerada estiveram associados a menos estigma internalizado. Esse resultado parece refletir episódios de mania do TAB, nos quais a autoestima exacerbada é acompanhada pela euforia, percepção destorcida de si e da realidade e menor insight. Durante esses episódios pode haver menos autoestigma, pois a excitação 
presente na fase de mania pode distrair os indivíduos dos sentimentos estigmatizantes (HOWLAND et al., 2016).

Neste estudo, a maioria dos pacientes estava em tratamento medicamentoso e foi classificada como aderente ao tratamento e, a não-adesão ao tratamento medicamentoso e os menores níveis de adesão, estiveram associados ao estigma internalizado. Estudo realizado na República Tcheca com 72 pacientes diagnosticados com transtorno depressivo apontou que uma menor adesão ao tratamento esteve associada a maiores taxas de autoestigma (SEDLACKOVA et al., 2015)

Outros estudos revelaram que o autoestigma esteve associado a menores níveis de adesão entre pessoas diagnosticadas com TAB (HOWLAND et al., 2016), pacientes com diagnóstico de espectro da esquizofrenia (UHLMANN et al., 2014) e pessoas com transtornos mentais em geral (KAMARADOVA et al., 2016). O estigma internalizado pode prejudicar a busca por ajuda, pois o medo da estigmatização e os esforços para evitar rótulos favorecem que os pacientes se isolem, acreditem menos na própria recuperação e potencializem a sintomatologia depressiva e menor autoeficácia sobre sua própria vida e condição mental (HOWLAND et al., 2016; SEDLACKOVA et al., 2015).

Neste estudo, no modelo de regressão linear múltiplo a variável "adesão" não foi apontada como preditora de estigma internalizado. É possível que a não adesão interfira no autoestigma por meio da elevação dos sintomas, pois na literatura a adesão ao tratamento é considerada crucial para o manejo da sintomatologia (PRASKO et al., 2016) e, no presente estudo, maior sintomatologia esteve associada ao estigma internalizado, inclusive no modelo de regressão linear múltiplo. A não adesão é um problema constante nos transtornos de humor e pode trazer tanto prejuízo quanto a doença em si; ter um fator estressor potencializando a não aderência é um grande obstáculo no caminho em busca da recuperação, por isso, estudos nessas áreas são importantes para conseguir intervenções que amenizem tantas dificuldades no cotidiano dos pacientes (HOWLAND et al., 2016; SEDLACKOVA et al., 2015; KAMARADOVA et al., 2016; PRASKO et al., 2016).

No presente estudo, a maioria dos participantes negou ter apresentado episódios de heteroagressão. Todavia, as pessoas que referiram ter agredido alguém previamente tiveram maior pontuação na ISMI e na subescala "aprovação do estereótipo", mas o histórico de heteroagressão não foi apontado como preditor de estigma internalizado, de acordo com o modelo de regressão múltiplo.

A heteroagressão esteve associada à "aprovação do estereótipo", o que pode sinalizar que essa dimensão do estigma internalizado seja mais proeminente entre pessoas com 
histórico de heteroagressão. Há um importante preconceito social de que o transtorno mental esteja ligado à imprevisibilidade e violência, e quando o paciente apropria-se desses rótulos está propenso a um aumento do estigma internalizado (MASCAYANO et al., 2016). Os rótulos e estereótipos de agressividade ligados aos diagnósticos de transtornos mentais também estão presentes entre crenças de profissionais de saúde, que podem colaborar para perpetuar o estigma (KANWAR et al., 2015). Além disso, os meios de comunicação tendem a propagar uma imagem de impulsividade e agressividade em relação a pessoas com transtornos mentais (KALISOVA et al., 2018).

Há estereótipos culturais que associam os transtornos mentais à agressividade, periculosidade e necessidade de hospitalização e reclusão para proteção de terceiros. Essas ideias negativas podem favorecer que o paciente tenha incertezas sobre o próprio autocontrole e internalizem dúvidas e inseguranças, o que fomenta o estigma internalizado (PAL; SHARAN; CHADDA, 2017; KAMARADOVA et al., 2016; MOSES, 2014; VEDANA et al., 2017).

Neste estudo, a maioria dos participantes referiu ter passado por internações psiquiátricas e o maior número de internações psiquiátricas esteve associado à maior pontuação na escala de estigma internalizado e nas subescalas "alienação", "aprovação do estereótipo", "percepção da discriminação" e "evitação social". Todavia, as internações psiquiátricas não foram apontadas como preditor de estigma internalizado de acordo com o modelo de regressão múltiplo.

As internações psiquiátricas podem favorecer elementos que intensificam o processo de internalização do estigma, tais como perceber a discriminação, assimilar, endossar e antecipar o preconceito (WANG et al., 2017). Essas internações também estão associadas à vergonha e à perda do empoderamento, da autoeficácia e da autoestima, além do sentimento de perda pelo controle do próprio tratamento e desvalorização. Tais fatores podem servir de precursores para a internalização do estigma. Além disso, a exposição ao estereótipo que o hospital psiquiátrico está ligado pode fazer com que esses pacientes se associem, de forma mais concreta, a rótulos de agressividade, de maior gravidade dos sintomas e ao fato de que pacientes psiquiátricos não conseguem viver em sociedade - o que colabora com o estigma internalizado, podendo fomentar os danos associados a ele (KAMARADOVA et al., 2016).

CHANG et al. (2016) verificaram as diferenças no estigma internalizado entre diferentes transtornos mentais em Taiwan e concluíram que pessoas que passaram por internações psiquiátricas tiveram uma maior pontuação na maior parte das subescalas da ISMI, exceto na "resistência ao estigma". PICCO et al. (2016) também chegaram ao 
consenso, em seu trabalho realizado em Singapura, com 280 participantes, que a hospitalização por transtorno metal associou-se com maiores resultados de estigma internalizado (CHANG et al., 2016; PICCO et al., 2016).

No presente estudo mais da metade dos participantes relatou tentativas prévias de suicídio. A literatura confirma que os diagnósticos de Transtorno Afetivo Bipolar e Depressão são associados a maior risco de suicídio (BROWN et al., 2000; ANDO et al., 2013; BOBO et al., 2018) se comparados com a população em geral, e os resultados que aqui constam contribuem com a literatura já existente.

Foi encontrada correlação entre maior quantidade de tentativas prévias de suicídio e maiores escores de estigma internalizado, e o modelo de regressão linear múltiplo mostrou que o histórico de tentativa prévia de suicídio foi preditor de maior pontuação na ISMI. A literatura sugere que a tentativa de suicídio pode ser um fator que potencializa o estigma internalizado, uma vez que o suicídio está ligado à discriminação, não aceitação social e a julgamentos, o que pode gerar sentimentos de vergonha e impotência nos pacientes (CARPINIELLO; PINNA, 2017). Esses achados ressaltam a importância do investimento em intervenções direcionadas à redução da internalização do estigma como forma de evitar danos ainda mais expressivos na qualidade de vida dos indivíduos.

Este estudo revelou que as tentativas de suicídio podem ser preditores de maior estigma internalizado e a literatura mostra que o estigma também pode ser um fator de risco para o comportamento suicida. Por exemplo, um estudo norte-americano realizado com 184 pacientes com transtornos mentais encontrou que o estigma percebido tem papel importante como fator de risco para o suicídio (WANG et al., 2017). Outro estudo, realizado em Hong Kong, revelou que $40 \%$ dos pacientes com transtorno mental dizem querer acabar com a própria vida devido à estigmatização (XU et al., 2017). Outra pesquisa realizada na Espanha com 71 pacientes diagnosticados com esquizofrenia constatou que pacientes com estigma internalizado apresentaram maior prevalência de ideação suicida no último ano e maior número de tentativas de suicídio (TOURINO et al., 2018). Estudo desenvolvido com 227 pessoas com transtorno mental desempregadas identificou que todos os componentes do estigma se associaram com a ideação suicida (OEXLE et al., 2018).

Uma das possíveis explicações para a associação entre o estigma internalizado e as tentativas de suicídio seria que este estigma internalizado está associado à desesperança, sofrimento emocional, angústia e baixa autoestima (CARPINIELLO; PINNA, 2017; BOBO et al., 2018). Além disso, o estigma internalizado faz com que a pessoa se sinta incapaz e 
improdutiva, o que gera sentimentos de alienação e não pertencimento, tornando-as mais suscetíveis ao comportamento suicida (FARRELLY et al., 2015).

Neste estudo foi encontrada uma correlação inversa entre esperança o estigma internalizado (na pontuação total da ISMI e em todas as cinco subescalas). Ademais, o modelo de regressão linear múltiplo revelou que o aumento de ponto na Escala de avaliação da esperança reduziu em um ponto o escore obtido na ISMI.

Esses resultados vão ao encontro de achados de estudos realizados com pacientes psicóticos (YANOS et al., 2008; VASS et al., 2015). Estudo transversal realizado com 102 pacientes com diagnóstico de espectro da esquizofrenia identificou que o estigma internalizado reduz a esperança e a autoestima (YANOS et al., 2008). Outro estudo no Reino Unido com 80 pacientes com transtornos psicóticos também mostrou que um dos efeitos do estigma é a falta de esperança e autoestima (VASS et al., 2015). Contudo, os resultados aqui apresentados não coincidem com os encontrados em um estudo transversal realizado em Singapura, com 280 pacientes diagnosticados com transtornos psicóticos, depressão e TOC, pois no referido estudo não houve associação significativa entre esperança e estigma internalizado (PICCO et al., 2016). É importante explorar as diferenças culturais e as especificidades relacionadas aos transtornos mentais que possam colaborar para a explicação dessas divergências entre os resultados obtidos.

Ao ser diagnosticado com uma doença crônica o indivíduo pode mudar a maneira como percebe o seu futuro, e essa mudança pode ser acentuada se o diagnóstico está relacionado a um transtorno mental, frequentemente associado a desconhecimento e mitos, que podem favorecer o estigma internalizado e pode ser uma das causas de altos níveis de estigma internalizado estarem ligados a baixos níveis de esperança (MACDOUGALL; VANDERMEER; NORMAN, 2015).

É possível que menor nível de esperança e estigma internalizado exerçam influência mútua, pois enquanto este estudo identificou que a esperança está associada a menor estigma internalizado, a literatura mostra que a aceitação de julgamentos estigmatizantes sobre os transtornos mentais está associada a menores níveis de esperança (LIVINGSTON; BOYD, 2010), e pacientes que endossam crenças negativas sobre as doenças mentais acabam sentindo-se mais desesperançados e desesperados em relação ao futuro, mesmo após o manejo de sintomas depressivos (FARRELY et al., 2015).

A esperança está associada com a maneira que o indivíduo percebe a própria a vida. Desse modo, pessoas com níveis de esperança mais elevados, geralmente, conseguem enfrentar os problemas com mais eficácia, pois são mais adaptáveis a fatores estressores e 
conseguem ter reações construtivas (HAYES et al., 2017). Por isso, a esperança tem papel fundamental na recuperação e manutenção da qualidade de vida dos pacientes com transtornos de humor (HAYES et al., 2017; PICCO et al., 2016). A esperança motiva e sustenta as crenças e perspectivas sociais e ocupacionais que o indivíduo tem dele próprio, assim, a desesperança age como precursora de sentimentos de fracasso e, posteriormente, a desistência de atividades (BERRY; GREENWOLD, 2017). Ter esperança está relacionado a ter melhor humor, melhor saúde e melhor capacidade para lidar com as adversidades do ciclo saúde-doença (PRASKO et al., 2016). 


\section{CONCLUSÃO}

Este estudo teve como objetivo investigar o estigma internalizado e as associações entre essa variável e variáveis sociodemográficas, clínicas, esperança e adesão ao tratamento entre pessoas com transtornos de humor.

$\mathrm{Na}$ amostra investigada predominaram mulheres, sem ensino superior, sem companheiro, sem trabalho e residindo com alguém. A maioria tinha transtorno afetivo bipolar, era aderente ao tratamento medicamentoso, relatou internações psiquiátricas, tentativas prévias de suicídio e negou episódios de heteroagressão.

Neste estudo, maiores níveis de estigma estiveram associados à maior sintomatologia, menor nível de esperança, tentativas prévias de suicídio, histórico de comportamento agressivo, internações psiquiátricas, não adesão ao tratamento e não ter trabalho. Assim, o estigma esteve associado a fatores estreitamente relacionados à sintomatologia, percepção de autocontrole, autoeficácia e independência, perspectiva sobre si mesmo e sobre o próprio futuro.

No modelo de regressão linear múltiplo estiveram associadas ao estigma as variáveis "trabalho", "tentativas de suicídio", "sintomas" e "esperança". Os profissionais de saúde, pessoas com transtorno de humor e familiares precisam estar preparados para reconhecer e manejar fatores potencialmente estigmatizantes.

Nesse estudo foram identificados fatores que podem conferir ao indivíduo maior vulnerabilidade ao estigma internalizado. Destaca-se que, de acordo com a literatura, alguns desses elementos são investigados como desfechos também acentuados pelo estigma. Assim, é possível que esses fatores e o estigma se reforcem mutuamente, gerando um ciclo vicioso.

São imperativas as intervenções capazes de amenizar o estigma internalizado e o presente estudo aponta fatores associados que podem ser abordados em estratégias individuais e coletivas com essa finalidade. Nesse sentido, é válido investigar os efeitos de diferentes estratégias sobre o estigma internalizado e seus preditores.

As principais limitações deste estudo foram o uso de uma amostra de conveniência reduzida pertencente a um único serviço, o delineamento transversal. É recomendável que futuras análises investiguem as variáveis presentes neste estudo em diferentes contextos. Contudo, esta pesquisa contribui de forma significativa para a melhor compreensão do estigma internalizado e dos fatores associados a esse fenômeno entre pessoas com transtornos de humor. 


\section{REFERÊNCIAS}

ABREU, L.N. Avaliação do impacto da comorbidade com transtornos ansiosos no comportamento suicida em pacientes com transtorno de humor. 2015. $119 \mathrm{f}$. Tese (Doutorado em Ciências da Saúde) - Faculdade de Medicina da Universidade de São Paulo, São Paulo. 2015.

AL-HARBI, K.S. Treatment-resistant depression: therapeutic trends, challenges, and future directions. Patient Preference and Adherence, v. 6, p. 369-388. 2012.

AMERICAN PSYCHIATRIC ASSOCIATION (APA). Manual Diagnóstico e Estatístico de Transtornos Mentais (DSM-V). 5. ed. Porto Alegre: Artesmed, 2014.

ANDO, S.; KASAI, K.; MATAMURA, M.; HASEGAWA, Y.; HIRAKAWA, H.; ASUKAI, N. Psychosocial factors associated with suicidal ideation in clinical patients with depression. Journal of affective disorders, v. 151, n. 2, p. 561-565. 2013.

ASRAT, B.; AYENALEM, A. E.; YIMER, T. Internalized Stigma among Patients with Mental Illness Attending Psychiatric Follow-Up at Dilla University Referral Hospital, Southern Ethiopia. Psychiatry journal, v. 2018. 2018

BARNEY L.J.; GRIFFITHS, K.M.; CHRISTENSEN H.; JORM A.F. Exploring the nature of stigmatising beliefs about depression and help-seeking: implications for reducing stigma. BMC Public Health, v. 9, n. 1, p. 61. 2009.

BERRY, C.; GREENWOOD, K. Beliefs in social inclusion: Invariance in associations among hope, dysfunctional attitudes, and social inclusion across adolescence and young adulthood. Development and psychopathology, v. 2017, p. 1-17. 2017

BINOTTO, A.L. Perfil epidemiológico de pacientes com transtornos mentais acompanhados na atenção primária à saúde. $76 \mathrm{f}$. Tese (Mestrado em Ciências da Saúde) Faculdade de Medicina de Ribeirão Preto da Universidade de São Paulo, Ribeirão Preto. 2014.

BOBO, W. V.; NA, P.J.; GESKE, J.R.; MCELROY, S.L.; FRYE, M.A.; BIERNACKA, J. M. The relative influence of individual risk factors for attempted suicide in patients with bipolar I versus bipolar II disorder. Journal of affective disorders, v. 225, p. 489-494. 2018.

BRASIL. CONSELHO NACIONAL DE SAÚDE. Resolução n. ${ }^{\circ}$ 466, de 12 de dezembro de 2012, que aprova as diretrizes e normas regulamentadoras de pesquisas envolvendo seres humanos. In: Diário Oficial da União, Poder Executivo, Brasília, DF, 2012.

BROHAN, E.; GAUCI, D.; SARTORIUS, N.; THORNICROFT, G. Self-stigma, empowerment and perceived discrimination among people with bipolar disorder or depression 
in 13 European countries: The GAMIAN-Europe study. Journal of affective disorders, v. 129, n. 1-3, p. 56-63, 2011.

BROWN, G. K. et al. Risk factors for suicide in psychiatric outpatients: a 20-year prospective study. Journal of consulting and clinical psychology, v. 68, n. 3, p. 371. 2000.

BUSBY, K.K.; SAJATOVIC, M. Review: Patient, treatment, and systems-level factors in bipolar disorder nonadherence: A summary of the literature. CNS neuroscience \& therapeutics, v.16, n.5, p.308-315. 2010.

CARPINIELLO, B.; PINNA, F. The reciprocal relationship between suicidality and stigma. Frontiers in psychiatry, v. 8, p. 35. 2017.

CERIT, C. et al. Stigma: a core factor on predicting functionality in bipolar disorder. Comprehensive Psychiatry, v. 53, n. 5, p. 484-489, 2012.

CHANG, C.C.; WU, T.H.; CHEN, C.Y.; LIN, C.Y. Comparing self-stigma between people with different mental disorders. J. Nerv. Ment. Dis., v. 204, n. 7, p. 547-553. 2016.

CINCULOVA, A.; PRASKO, J.; KAMARADOVA, D.; OCISKOVA, M.; LATALOVA, K.; VRBOVA, K.; KUBINEK, R.; MAINERIVA, B.; GRAMBAL, A.; TICHACKOVA, A. Adherence, self-stigma and discontinuation of pharmacotherapy in patients with anxiety disorders-cross-sectional study. Neuro endocrinology letters, v. 38, n. 6, p. 429-426. 2017.

CLAYTON, J. et al. Sustaining hope when communicating with terminally ill patients and their families: a systematic review. Psych Oncol, v. 17, n. 7, p. 641-659, 2008.

CLEMENT, S.; SCHAUMAN, O.; GRAHAM, T.; MAGGIONI, F.; EVANS-LACKO, S.; BEZBORODOVS, N.; MORGAN, C.; RUSCH, N.; BROWN, J.S.L.; THORNICROFT, G. What is the impact of mental health-related stigma on help-seeking? A systematic review of quantitative and qualitative studies. Psychological Medicine, v. 45, n. 1, p. 11-27. 2015.

CLEMENTE, A.S. Concepções dos psiquiatras sobre o Transtorno Bipolar do Humor e sobre o estigma a ele associado. $304 \mathrm{f}$. Tese (Doutorado em Ciências da Saúde) - Fundação Oswaldo Cruz, Belo Horizonte. 2015.

CONCATO, J.; FEINSTEIN, A. R.; HOLFORD, T. R. The risk of determining risk with multivariable models. Annals of internal medicine, v. 118, n. 3, p. 201-210. 1993.

CORRIGAN, P. W.; WASSEL, A. Understanding and influencing the stigma of mental illness. Journal of psychosocial nursing and mental health services, v. 46, n. 1, p. 42-48, 2008

CORRIGAN, P.; KERR, A.; KNUDSEN, L. The stigma of mental illness: explanatory models and methods for change. Appl Prev. Psychol., v. 11, n. 3, p. 179-190. 2005a. 
CORRIGAN, P.; WATSON, A.; HEYRMAN, M.; WARPINSKI, A.; GRACIA, G.; SLOPEN, N. et al. Structural stigma in state legislation. Psychiatr. Serv., v. 56, n. 5, p. 557563. $2005 b$.

COUTINHO, L.M.S.; MATIJASEVICH, A.; SCAZUFCA, M.; MENEZES, P.R. Prevalência de transtornos mentais comuns e contexto social: análise multinível do São Paulo Ageing e Health Study. Cad. Saúde Pública, v. 30, n. 9, p. 1875-1883. 2014.

CRIPPA, J.A.S.; SANCHES, R.F.; HALLAK, J.E.C.; LOUREIRO, S.R.; ZUARDI, A.W. Factor structure of Bech's version of the Brief Psychiatric Rating Scale in Brazilian patients. Braz. J. Med. Biol. Res., v. 35, n. 10, p. 1209-1213. 2002.

CRIPPA, J.A.S.; SANCHES, R.F.; HALLAK, J.E.C.; LOUREIRO, S.R.; ZUARDI, A.W. A structure interview guide increases Brief Psychiatric Rating Scale reliability in raters with clinical experience. Acta Psychiatr. Scand, v. 103, p. 465-470. 2001.

CRUZ, L.P.; MIRANDA, P.M.; VEDANA. K.G.G.; MIASSO, A.I. Medication therapy: adherence, knowledge and difficulties of elderly people from bipolar disorder. Revista Latino-Americana da Enfermagem, v. 19, n. 4, p. 944-952. 2011.

DAL-FARRA, R.A.; LOPES, P.T.C. Métodos mistos de pesquisa em educação pressupostos teóricos. Nuance: estudos sobre Educação, v. 24, n. 3, p. 67-80. 2014.

DELGADO, A.B.; LIMA, M.L. Contributo para a validação concorrente de uma médica de adesão aos transtornos. Psicologia, Saúde \& Doenças, v. 2, n. 2, p. 81-100. 2001.

FARRELLY, S.; JEFFERY, D.; RÜSCH, N.; WILLIAMS, P.; THORNICROFT, G.; CLEMENT, S. The link between mental health-related discrimination and suicidality: service user perspectives. Psychological medicine, v. 45, n. 10, p 2013-2022. 2015.

FELICISSIMO, F.B.; FERREIRA, G.C.L.; SOARES, R.G.; SILVEIRA, P.S.; RONZANI, T.M. Estigma internalizado e autoestima: uma revisão sistemática da literatura. Revista Psicologia: Teoria e Pratica, São Paulo, v. 15, n. 1, p. 116-129. 2013.

GIRMA, E.; TESFAYE, M.; FROESCHL, G.; MÖLLER-LEIMKÜHLER, A.M.; DEHNING, S.; MÜLLER, N. Facility based cross-sectional study of self stigmaself-stigma among people with mental illness: towards patient empowerment approach. International journal of mental health systems, v. 7, n.1, p. 21. 2013.

GOFFMAN, E. Estigma: notas sobre a manipulação da identidade deteriorada. Rio de Janeiro: LTC, 1988. 158p.

HANAFIAH, A.N.; BORTEL, T.V. A qualitative exploration of the perspectives of mental health profissionals on stigma and discrimination of mental illness in Malaysia. International Journal of Mental Health Systems, v. 9, n. 1, p. 10. 2015. 
HARRIS, J.I.; FARCHMIN, L.; STULL, L.; BOYD, J.; SCHUMACHER, M.; DRAPALSKI, A.L. Prediction of changes in self-stigma among veterans participating in partial psychiatric hospitalization: The role of disability status and military cohort. Psychiatric rehabilitation journal, v. 38, n. 2, p. 179. 2015.

HAYES, L.; HERRMAN, H.; CASTLE, D.; HARVEY, C. Hope, recovery and symptoms: the importance of hope for people living with severe mental illness. Australasian Psychiatry, v. 25, n. 6, p. 583-587. 2017.

HAYWARD, P. et al. Stigma and self-esteem in manic depression: an exploratory study. Journal of affective disorders, v. 69, n. 1-3, p. 61-67, 2002.

HOWLAND, M.; LEVIN, M.; BLIXEN, J.; TATSUOKA, C.; SAJATOVIC, M. Mixedmethods analysis of internalized stigma correlates in poorly adherent individuals with bipolar disorder. Comprehensive Psychiatry, v. 70, p. 174-180. 2016.

KALISOVA, L. et al. Factors influencing the level of self-stigmatisation in people with mental illness. International Journal of Social Psychiatry, v. 2017, p. 1-7. 2017.

KAMARADOVA, D. et al. Connection between self-stigma, adherence to treatment, and discontinuation of medication. Patient preference and adherence, v. 10, p. 1289, 2016.

KANWAR, A. Mental Illness and Stigma: Has Psychiatry Done more Harm than Good? Indian Journal Psychol Medicine, v. 37, n. 2, p.181-183. 2015.

KRAJEWSKI, C.; BURAZERI, G.; BRAND, H. Self-stigma, perceived discrimination and empowerment among people with a mental illness in six countries: Pan European stigma study. Psychiatry Research, v. 210, n. 3, p. 1136-1146, 2013

KESSLER, R.C. et al. The global burden of mental disorders: an update from the Who World Mental Health (WMH) surveys. Epidemol. Psichiat. Soc., v. 18, n. 1, p. 23-22. 2009.

LI, J.; HUANG, Y. G.; RAN, M. S.; FAN, Y.; CHEN, W.; EVANS-LACKO, S.; THORNICROFT, G. Community-based comprehensive intervention for people with schizophrenia in Guangzhou, China: Effects on clinical symptoms, social functioning, internalized stigma and discrimination. Asian journal of psychiatry, v. 34, p. 21-30. 2018.

LIU, N. H., CONTRERAS, O., MUÑOZ, R. F., \& LEYKIN, Y. Assessing suicide attempts and depression among Chinese speakers over the internet. Crisis: The Journal of Crisis Intervention and Suicide Prevention, v. 35, n. 5, p. 322. 2014.

LIVINGSTON, J.D., BOYD, J.E. Correlates and consequences of internalized stigma for people living with mental illness: a systematic review and meta-analysis. Soc. Sci. Med., v. 71, n. 12, p. 2150-2161. 2010. 
MACDOUGALL, A.G.; VANDERMEER, M.R.J.; NORMAN, R.M.G. Negative future self as a mediator in the relationship between insight and depression in psychotic disorders. Schizophrenia Research, v.165, n.1, p.66-69, 2015.

MASCAYANO, F.; ARMIJO, J.E.; HSIN YANG, L. Addressing stigma relating to mental illness in low- and middle-income countries. Frontiers in Psychiatry/Affective Disorders and Psychosomatic Research, v. 6, n. 38, p. 1-4. 2015.

MATHIAS, K.; KERMODE, M.; SAN SEBASTIAN, M.; KOSCHORKE, M.; GOICOLEA, I. Under the banyan tree - exclusion and inclusion of people with mental disorders in rural North India. BMC Public Health, v. 15, n. 1, p. 446. 2015.

MCALLISTER-WILLIAMS, R.H.; FERRIER, I.N. Pharmacological management of bipolar affective disorder. Psychiatry, v. 8, n. 4, p. 120-124. 2009.

MESTDAGH, A.; HANSEN, B. Stigma in patients with schizophrenia receiving community mental health care: a review of qualitative studies. Social Psychiatry Psychiatric Epidemiology, v. 49, n. 1, p. 79-87. 2014.

MIASSO, A.I.; CASSIANE, S.H.B.; PEDRÃO, L.J. Transtorno afetivo bipolar e a ambivalência em relação à terapia medicamentosa: analisando as condições causais. Revista da Escola de Enfermagem da USP, São Paulo, v. 45, n. 2, p. 433-441. 2011.

MIGUEL, E.C.; GENTIL, V.; GATTAZ, W.F. Clínica psiquiátrica. 2a edição. São Paulo: Manole, 2011.

MONTGOMERY, D. C., Design and Analysis of Experiments. $5^{\mathrm{a}}$ ed. Nova Iorque: John Wiley \& Sons, Inc., 2000.

MOROTE, R.; HJEMDAL, O.; KRYSINSKA, K.; URIBE, P.M.; CORVELEYN, J. Resilience or hope? Incremental and convergent validity of the resilience scale for adults (RSA) and the Herth hope scale (HHS) in the prediction of anxiety and depression. BMC psychology, v. 5, n. 1, p. 36. 2017.

MOSES, T. What helps or undermines adolescents' anticipated capacity to cope with mental illness stigma following psychiatric hospitalization. International Journal of Social Psychiatry, v. 61, n. 3, p. 215-224. 2014.

NERY, F.C. Estudo das propriedades psicrométricas da "Escala de Estigma Internalizado para Transtorno Mental - ISMI-BR". 167 f. Tese (Mestrado em Psicologia) - Universidade Federal de Juiz de Fora. 2013.

OCISKOVA, M.; PRASKO, J.; KAMARADOVA, D.; LATALOVA, K.; KURFÜRST, P.; DOSTÁLOVÁ, L.; TICHÁČKOVÁ, A. Self-stigma in psychiatric patients-standardization of the ISMI scale. Neuroendocrinology Letters, v. 35, n. 7. 2014. 
OCISKOVA, M., PRASKO, J., VRBOVA, K., KASAlOVA, P., HOLUBOVA, M., GRAMBAL, A., \& MACHU, K. Self-stigma and treatment effectiveness in patients with anxiety disorders - a mediation analysis. Neuropsychiatric Disease and Treatment, v. 14, p. 383. 2018.

OEXLE, N.; RÜSCH, N.; VIERING, S.; WYSS, C.; SEIFRITZ, E.; XU, Z.; KAWOHL, W. Self-stigma and suicidality: a longitudinal study. European Archives of Psychiatry and Clinical Neuroscience, v. 267, n. 4, p. 359-361. 2017.

OLÇUN, Z.; \& ALTUN, Ö.Ş. The correlation between schizophrenic patients' level of internalized stigma and their level of hope. Archives of psychiatric nursing, v. 31, n. 4, p. 332-337. 2017.

OLIVEIRA, S.E.H.; ESTEVES, F.G.; PEREIRA, E.G.; CARVALHO, M.; BOYD, J.E. The Internalized Stigma of Mental Illness: Cross-Cultural Adaptation and Psychometric Properties of the Portuguese Version of the ISMI Scale. Community Mental Health Journal, v. 51, n. 5, p. 606-612. 2015a.

OLIVEIRA, S.E.H.; ESTEVES, F.; CARVALHO, H. Clinical profiles of stigma experiences, self-esteem and social relationships among people with schizophrenia, depressive, and bipolar disorders. Psychiatry Research, v. 229, n. 1-2, p. 167-173. 2015b.

ORGANIZAÇÃO MUNDIAL DE SAÚDE (OMS). Classificação Estatística Internacional de Doenças e Problemas Relacionados à Saúde - CID-10. Genebra: Organização Mundial de Saúde; 2008. Disponível em: <http://www.datasus.gov.br/cid10/V2008/cid10.htm>. Acesso em: 05 de fevereiro de 2017.

ORGANIZAÇÃO MUNDIAL DE SAÚDE (OMS). Integração da saúde mental nos cuidados de saúde primários. Uma perspectiva global. Genebra: Organização Mundial de Saúde. 2009.

PAGano, M.; GAUVREAU, K. Princípios de Bioestatística. 2 ed. São Paulo: Cengage Learning, 2011.

PAL, A.; SHARAN, P.; CHADDA, R. K. Internalized stigma and its impact in Indian outpatients with bipolar disorder. Psychiatry research, v. 258, p. 158-165, 2017.

PALLANT, J. SPSS Survival Manual: A Step by Step Guide to Data Analysis using SPSS for Windows. In: Journeys in Survey Research, 4th edition, Open University Press. 2010.

PICCO, L.; PANG, S.; LAU, Y.W.; JEYAGURUNATHAN, A.; SATGHARE, P.; ABDIN, E.; VAINGANKAR, J.A.; LIM, S.; POH, C.L.; CHONG, S.A.; SUBRAMANIAM, M. Internalized estigma among psychiatric outpatients: Associations with quality of life, functioning, hope and self-steem. Psychiatry Research, v. 246, p. 500-506. 2016. 
POMPILI, M.; SERAFINI, G.; DEL CASALE, A.; RIGUCCI, S.; INNAMORATI, M.; GIRARDI, P.; TATARELLI, R.; LESTER, D. Improving adherence in mood disorders: the struggle against relapse, recurrence and suicide risk. Expert Rev Neurotherapeutics, v. 9, n.7, p. 985-1004. 2009.

POTTER, P.A.; PERRY, A.G.; STOCKERT, P.A.; HALL, A.M. Fundamentos de Enfermagem. 8a ed. Rio de Janeiro: Elsevier, 2013.

PRASKO J.; OCISKOVA M.; GRAMBAL A. et al. Personality features, dissociation, selfstigma, hope, and the complex treatment of depressive disorder. Neuropsychiatr Dis Treat., v. 12, p. 2539-2552. 2016.

RAZZOUK, D. Por que o Brasil deveria priorizar o tratamento da depressão na alocação dos recursos da saúde? Epidemiol. Serv. Saúde, v. 25, n. 4, p. 845-848. 2016.

RÜSCH, N., MÜLLER, M., LAY, B., CORRIGAN, P. W., ZAHN, R., SCHÖNENBERGER, T., BLEIKER, M., LENGLER, S., BLANK, C., RÖSSLER, W. Emotional reactions to involuntary psychiatric hospitalization and stigma-related stress among people with mental illness. European Archives of Psychiatry and Clinical Neuroscience, v. 264, n. 1, p. 35-43. 2014.

TOURINO, R. et al. Suicidal risk, hopelessness and depression in patients with schizophrenia and internalized stigma. Actas espanolas de psiquiatria, v. 46, n. 2, p. 33-41, 2018.

SALLES, M.M.; BARROS, S. Representações sociais de usuários de um Centro de Atenção Psicossocial e pessoas de sua rede sobre doença mental e inclusão social. Saúde Sociedade, São Paulo, v. 22, n. 4, p. 1059-1071. 2013.

SANSONE, R.A.; SANSONE, L.A. Antidepressant Adherence: Are Patients Taking Their Medications? Innov Clin Neurosci, v. 9, n. 5-6, p. 41-46. 2012.

SARKAR, S., BALHARA, Y. P. S., KUMAR, S., SAINI, V., KAMRAN, A., PATIL, V.; SINGH, S.; GYAWALI, S. Internalized stigma among patients with substance use disorders at a tertiary care center in India. Journal of ethnicity in substance abuse, p. 1-14. 2017.

SARTORE, A.C.; GOSSI, S.A.A. Escala de Esperança de Hearth - instrumento adaptado e validado para a língua portuguesa. Rev. Esc. Enferm. USP, São Paulo, v. 42, n. 2, p. 227 232. 2008.

SCUSSEL, F.; SALVADOR, L.C.; BRANDÃO, L.S.; FEIER, G. Perfil clínico dos pacientes com Transtorno Bipolar atendidos em um ambulatório especializado na região sul catarinense. Arq. Catarin. Med, v. 45, n. 4, p. 3-10. 2016.

SEDLACKOVA, Z.; KAMARADOVA, D.; PRASKO, J.; LÁTALOVÁ, K.; OCISKOVÁ, M.; CINCULOVÁ, A.; KUBINEK, R.; MAINEROVÁ, B.; TICHACKOVA, A.; VRBOVÁ, 
K. Treatment adherence and self-stigma in patients with depressive disorder in remission-a cross-sectional study. Neuroendocrinol Lett, v. 36, n. 2, p. 171-177. 2015

SEMERAU, M.; EVANS-LACKO, S.; KOSCHORKE, M.; ASHENAFI, L.; THORNICROFT, G. Stigma and discrimination related to mental illness in low- and middleincome countries. Epidemiology and Psychiatric Sciences, v. 1, n. 19, p. 1-14. 2015.

SHRIVASTAVA, A.; BUREAU, Y.; REWARI, N.; JOHNSTON, M. Clinical risk of stigma and discrimination of mental illnesses: Need for objective assessment and quantification. Indian Journal of Psychiatry, v. 55, n. 2, p. 178-182. 2013.

SNYDER CR. Hope theory: rainbows in the mind. Psychol Inq., v. 13, n. 4, p. 249-275. 2002.

SOUZA, R.T. Fisiopatologia do Transtorno Afetivo Bipolar e o efeito do tratamento com lítio: enfoque em neuroproteção e função mitocondrial. 138 f. Tese (Doutorado em Ciências da Saúde) - Faculdade de Medicina da Universidade de São Paulo, São Paulo. 2014.

TRIOLA, M. Introdução à Estatística. 7 ed. Rio de Janeiro: Livros Técnicos e Científicos (LTC), 1999.

TRIOLA, M. Introdução à Estatística. 9 ed. Rio de Janeiro: Livros Técnicos e Científicos (LTC), 2005.

UHLMANN, C., KAEHLER, J., HARRIS, M. S., UNSER, J., AROLT, V., \& LENCER, R. (2014). Negative impact of self-stigmatization on attitude toward medication adherence in patients with psychosis. Journal of Psychiatric Practice, v. 20, n. 5, p. 405-410. 2014.

VASS, V. et al. How stigma impacts on people with psychosis: The mediating effect of selfesteem and hopelessness on subjective recovery and psychotic experiences. Psychiatry research, v. 230, n. 2, p. 487-495, 2015.

VYAVAHARKAR, M. et al. Relationships between stigma, social support, and depression in HIV-infected African American women living in the rural Southeastern United States. Journal of the Association of Nurses in AIDS Care, v. 21, n. 2, p. 144-152, 2010.

VEDANA, K. G. G., SILVA, D. R. A., MIASSO, A. I., ZANETTI, A. C. G., \& BORGES, T. L. The Meaning of Stigma for People with Mental Disorders in Brazil. Issues in mental health nursing, v. 38, n. 12, p. 1022-1029. 2017.

WANG, K. et al. Emotional clarity as a buffer in the association between perceived mental illness stigma and suicide risk. Stigma and health, v. 1, n. 4, p. 252, 2016

WORLD HEALTH ORGANIZATION (WHO). Depression: what is depression? Geneva: WHO, 2012. Disponível em: <http://www.who.int/mental_health/management/depression/ definition/en/>. Acesso em 05 de fevereiro de 2017. 
WORLD HEALTH REPORT. Mental health: new understanding, new hope. Geneva, World Health Organization, 2001.

XU Z.; MAYER B.; MÜLLER M.; HEEKEREN K.; THEODORIDOU A.; DVORSKY D.; METZLER S.; OEXLE N.; WALITZA S.; RÖSSLER W.; RÜSCH N. Stigma and suicidal ideation among young people at risk of psychosis after one year. Psychiatry Research, v. 243, p. 219-224. 2017.

XU, Z.; MÜLLER, M.; LAY, B.; OEXLE, N.; DRACK, T.; BLEIKER, M.; LENGLER, S.; BLANK, C.; VETTER, S.; ROSSLER, W.; RÜSCH, N. Involuntary hospitalization, stigma stress and suicidality: a longitudinal study. Social psychiatry and psychiatric epidemiology, v. 53, n. 3, p. 309-312. 2018.

YANOS, P. T. et al. Group-based treatment for internalized stigma among persons with severe mental illness: Findings from a randomized controlled trial. Psychological Services, v. 9, n. 3, p. 248,2012

YANOS, P.T., ROE, D., MARKUS, K., LYSAKER, P.H., 2008. Pathways between internalized stigma and outcomes related to recovery in schizophrenia spectrum disorders. Psychiatr. Serv., v. 59, n. 12, p. 1437-1442. 2008.

ZAGO, A.; TOMASI, E.; DEMORI, C.C. Adesão ao tratamento medicamentoso dos usuários de centros de atenção psicossocial com transtorno de humor e esquizofrenia. Rev. Eletrônica Saúde Mental Álcool Drog, v.11, n. 1, p. 224-233, 2015.

ZUARDI, A.W.; LOUREIRO, S.R.; E.; RODRIGUES, C.R.C.; CORREA, A.J.; GLOCK, S.S. Estudo da estrutura fatorial, fidedignidade e validade da tradução e adaptação para o português da Escala de Avaliação Psiquiátrica Breve (BPRS) modificada. ABP-APAL, v.16, n. 2, p. 63-68, 1994. 


\section{APENDICES}

\section{Apêndice 1 - Questionário sociodemográfico}

\section{Questionário sociodemografico}

(Dados informados pelo paciente)

1. Data da entrevista:

2. Número do paciente no banco de dados

3. Entrevistador:

4. Naturalidade

5. Sexo: 1.Feminino ( ) 2.Masculino ( )

6. Data de nascimento:

7. Sabe ler /escrever: $\overline{1 . N a ̃ o(~) ~} 2 \cdot \operatorname{Sim}($ )

8. Escolaridade:
1. Não estudou em escola regular ( )
5. Médio completo ( )

2. Fundamental incompleto ( )

6. Superior incompleto ( )

3. Fundamental completo ( )

7. Superior completo ( )

4. Médio incompleto ( )

8. Outro( )

9. Repetiu alguma serie? 1. Não ( ) 2.Sim ( ) Quantas vezes?

10. Situação conjugal?
1.Solteiro ( )
3.Separado/divorciado ( )
4.Viúvo ( )

2.Casado/com companheiro fixo ( )

11. Qual a sua ocupação/profissão

12. Exerce a profissão atualmente? 1.Não ( ) 2.Sim ( )

13. Recebe auxilio benefício? $\quad$ 1.Não ( ) 2.Sim ( )

14. Contribui com a renda mensal da familia? 1.Não ( ) 2.Sim ( )

15. Auxilia nas tarefas de casa (Ex: limpar a casa, ir ao mercado, cuidar de crianças)? 1.Não ( ) 2.Sim ( )

16. Você mora com:

1.Familia ( )

2.Amigos ( )
3.Sozinho ( )

4.Outro

$$
\text { . Sim ( ) }
$$

Qual?

1.Não ( )

Frequência?

\section{Dados do adoecimento e tratamento do paciente}

18. Diagnóstico referido: Você sabe me dizer o nome da doença psiquiátrica/mental que você tem? $\quad$ 1.Não（） 2.Sim（） Qual é o nome?

19. Idade que recebeu o diagnóstico médico anos.

20. Idade que usou medicação psiquiátrica ( com indicação medica) pela primeira vez anos

Qual?

21. Hospitalizações psiquiátricas? 1.Não ( )

2.Sim ( )

Quantas?

22. Idade da primeira internação psiquiátrica anos

23. Idade da última internação psiquiátrica anos 
24. Alguma vez você tentou suicídio? 1.Nâo（） 2.Sim（ ) Quantas?

25. Alguma vez se cortou ou se feriu propositalmente? 1.Não ( )

2. $\operatorname{Sim}()$

26. Após o início da doença alguma vez ficou violento e agrediu alguém fisicamente? 1.Não ( ) 2.Sim ( )

27. Alguma vez você foi contido (amarrado) por profissionais de saúde? 1.Não ( ) 2.Sim ( ) Como?

28. Atualmente está fazendo algum acompanhamento, terapia ou atendimentos em serviço de saúde ou clinicas (Por exemplo: psicoterapia, grupos, terapia ocupacional, atendimento psicológico, medicina alternativa)?

1. Nẫo( ) 2. Sim( ) Qual?

Há quanto tempo?

Ficha de identificação

Numero Prontuário

Nome do paciente:

Cidade:

Diagnostico (CID 10)

Medicamentos prescritos (dose e frequência da administração):

Observaçōes: 


\section{Apêndice 2 - Termo de Consentimento Livre Esclarecido (TCLE) \\ TERMO DE CONSENTIMENTO LIVRE E ESCLARECIDO}

\section{Prezado Paciente}

Venho convidar você para participar da pesquisa "Estigma internalizado, suporte social, esperança e adesão ao tratamento entre pessoas com transtornos de humor" que tem como objetivo avaliar o estigma internalizado, suporte social, esperança e adesão ao tratamento entre pessoas com transtornos de humor.

Assim, solicito que você responda alguns questionários sobre esperança, estigma internalizado, suporto social, sintomas do transtorno psiquiátrico (depressão e/ou mania) e adesão ao tratamento. A entrevista será realizada no serviço de saúde em local privativo para que o senhor(a) sinta-se seguro. A aplicação desses questionários dura em média 40 minutos. Esclareço que você é livre para decidir se quer ou não participar da pesquisa. A sua identidade e toda informação que você der serão mantidas em segredo. A decisão de não participar da pesquisa não vai afetar seu atendimento no serviço de saúde. Você não será pago e não terá gastos para participar desta pesquisa.

Também peço a autorização do senhor(a) para ter acesso as seguintes informações do prontuário: diagnóstico e prescrição de medicamentos.

Comprometo-me a dar maiores informações e esclarecimento, se você tiver duvidas a respeito da pesquisa. Neste caso, é possível entrar em contato com as pesquisadoras pelo telefone (16) 3315-3408 ou e-mail: kellygiacchero@eerp.usp.br; dayane.rosa.santos@usp.br e com o Comitê de Ética em Pesquisa da EERP pelo telefone (16) 3315-9197 ou no endereço Av. Bandeirantes, 3.900 de segunda à sexta das $8 \mathrm{~h}$ às $17 \mathrm{~h}$.

O senhor(a) tem direito à indenização caso tenha dano por causa da sua participação na pesquisa, por parte do pesquisador e das instituições envolvidas na pesquisa. Os riscos e/ou desconforto de participação da pesquisa estão relacionados ao tempo gasto para responder os questionários e ao desconforto em falar sobre o estigma internalizado e/ou sintomas do transtorno psiquiátrico. Para reduzir esses problemas, poderemos escutá-los, podemos falar sobre outro assunto ou interromper a pesquisa, de acordo com suas necessidades. Estaremos aptos a oferecer apoio ao senhor(a) durante toda a entrevista e prontamente dispostos a oferecer suporte caso ocorra algum desconforto. Sua participação poderá oferecer a oportunidade de falar sobre assuntos de seu interesse.

$\mathrm{Se}$ o(a) Sr(a) aceitar participar dessa pesquisa, será de forma voluntária e deverá assinar este termo de consentimento e ficará com uma via, também assinada por mim. Caso precise, pode entrar em contato comigo por qualquer motivo, inclusive para deixar de participar da pesquisa a qualquer momento, sem que o(a) $\operatorname{Sr}$ (a) sofra qualquer prejuízo por parte do pesquisador. Ao finalizar o estudo, os resultados serão divulgados em diversos meios de comunicação (como revistas científicas).

O Comitê de Ética em Pesquisa (CEP) tem a finalidade de garantir a manutenção dos direitos humanos, protegendo eticamente os participantes de pesquisas, pois avalia as pesquisas em todas as etapas dos estudos que envolvem seres humanos, desde a elaboração do projeto até o relatório final. Ressaltamos que o desenvolvimento da presente pesquisa foi aprovado pelo CEP-EERP.

Coloco-me à disposição para quaisquer esclarecimentos.

Kelly Graziani Giacchero Vedana Pesquisador responsável
Dayane Rosa Alvarenga Silva Aluna de mestrado

$\mathrm{Eu}$, declaro que estou devidamente informado(a) e esclarecido(a) sobre a pesquisa e os procedimentos nela envolvidos e concordo em participar desta pesquisa. Recebi uma via deste termo de consentimento livre e esclarecido e me foi dada a oportunidade de ler e esclarecer as minhas dúvidas.

Local:__ Data: ___ _ _ _

(O documento será assinado em duas vias e uma via será fornecida ao participante) 
ANEXOS

Anexo 1 - Escala de Estigma Internalizado - ISMI-BR

A) Estigma Internalizado (ISMI)

Neste questionário, será usado o termo "transtorno mental", mas, por favor, PENSE NISTO USANDO O TERMO QUE VOCÊ ACHA QUE MELHOR SE APLICA.

Para cada questão, por favor, diga se você discorda totalmente (1), discorda (2), concorda (3), ou concorda totalmente (4).

\begin{tabular}{|c|c|c|c|c|}
\hline Proposições & $\begin{array}{c}\text { Discordo } \\
\text { totalmente }\end{array}$ & Discordo & Concordo & $\begin{array}{r}\text { Concordo } \\
\text { totalmente }\end{array}$ \\
\hline $\begin{array}{l}\text { 1. Você se sente fora de lugar no mundo por ter um } \\
\text { transtorno mental. }\end{array}$ & 1 & 2 & 3 & 4 \\
\hline $\begin{array}{l}\text { 2. Pessoas com transtomo mental tendem a ser } \\
\text { violentas. }\end{array}$ & 1 & 2 & 3 & 4 \\
\hline $\begin{array}{l}\text { 3. As pessoas te discriminam por você ter um } \\
\text { transtorno mental. }\end{array}$ & 1 & 2 & 3 & 4 \\
\hline $\begin{array}{l}\text { 4. Você evita se aproximar das pessoas que não tem } \\
\text { transtorno mental para evitar rejeição. }\end{array}$ & 1 & 2 & 3 & 4 \\
\hline $\begin{array}{l}\text { 5. Você fica envergonhado ou constrangido por ter } \\
\text { um transtorno mental. }\end{array}$ & 1 & 2 & 3 & 4 \\
\hline $\begin{array}{l}\text { 6. Pessoas com transtorno mental não deveriam se } \\
\text { casar. }\end{array}$ & 1 & 2 & 3 & 4 \\
\hline $\begin{array}{l}\text { 7. As pessoas com transtorno mental fazem } \\
\text { importantes contribuições para a sociedade. }\end{array}$ & 1 & 2 & 3 & 4 \\
\hline $\begin{array}{l}\text { 8. Você se sente inferior aos outros que não possuem } \\
\text { transtorno mental. }\end{array}$ & 1 & 2 & 3 & 4 \\
\hline $\begin{array}{l}\text { 9. Você não se socializa tanto quanto você } \\
\text { costumava porque seu transtorno mental poderia } \\
\text { te fazer parecer ou se comportar "estranho". }\end{array}$ & 1 & 2 & 3 & 4 \\
\hline $\begin{array}{l}\text { 10. Pessoas com transtorno mental não podem viver } \\
\text { uma vida boa, uma vida satisfatória. }\end{array}$ & 1 & 2 & 3 & 4 \\
\hline $\begin{array}{l}\text { 11. Você não fala muito sobre você mesmo porque } \\
\text { você não quer incomodar os outros com o seu } \\
\text { transtorno mental. }\end{array}$ & 1 & 2 & 3 & 4 \\
\hline $\begin{array}{l}\text { 12. Imagens negativas sobre o transtorno mental te } \\
\text { mantém afastado do mundo "normal". }\end{array}$ & 1 & 2 & 3 & 4 \\
\hline $\begin{array}{l}\text { 13. Estar rodeado por pessoas que não tem um } \\
\text { transtorno mental te faz sentir fora de lugar ou } \\
\text { inadequado. }\end{array}$ & 1 & 2 & 3 & 4 \\
\hline $\begin{array}{l}\text { 14. Você se sente à vontade quando está em público } \\
\text { na companhia de uma pessoa com transtorno } \\
\text { mental. }\end{array}$ & 1 & 2 & 3 & 4 \\
\hline $\begin{array}{l}\text { 15. As pessoas frequentemente te tratam com } \\
\text { condescendência, ou te tratam como criança }\end{array}$ & 1 & 2 & 3 & 4 \\
\hline
\end{tabular}




\begin{tabular}{|c|c|c|c|c|}
\hline Proposições & $\begin{array}{l}\text { Discordo } \\
\text { totalmente }\end{array}$ & Discordo & Concordo & $\begin{array}{l}\text { Concordo } \\
\text { totalmente }\end{array}$ \\
\hline \multicolumn{5}{|l|}{ apenas porque você tem um transtorno mental. } \\
\hline $\begin{array}{l}\text { 16. Você está desapontado consigo mesmo por ter } \\
\text { um transtorno mental. }\end{array}$ & 1 & 2 & 3 & 4 \\
\hline $\begin{array}{l}\text { 17. Ter um transtorno mental tem prejudicado sua } \\
\text { vida. }\end{array}$ & 1 & 2 & 3 & 4 \\
\hline $\begin{array}{l}\text { 18. As pessoas percebem que você tem um } \\
\text { transtorno mental pela sua aparência. }\end{array}$ & 1 & 2 & 3 & 4 \\
\hline $\begin{array}{l}\text { 19. Por você ter um transtorno mental você precisa } \\
\text { que os outros tomem a maioria das decisões por } \\
\text { você. }\end{array}$ & 1 & 2 & 3 & 4 \\
\hline $\begin{array}{l}\text { 20. Você evita situações sociais para proteger sua } \\
\text { família ou amigos do constrangimento. }\end{array}$ & 1 & 2 & 3 & 4 \\
\hline $\begin{array}{l}\text { 21. Pessoas sem transtorno mental possivelmente } \\
\text { não conseguiriam te compreender. }\end{array}$ & 1 & 2 & 3 & 4 \\
\hline $\begin{array}{l}\text { 22. As pessoas te ignoram ou não te levam a sério } \\
\text { apenas porque você tem um transtorno mental. }\end{array}$ & 1 & 2 & 3 & 4 \\
\hline $\begin{array}{l}\text { 23. Você não pode contribuir com nada para a } \\
\text { sociedade por você ter um transtorno mental. }\end{array}$ & 1 & 2 & 3 & 4 \\
\hline $\begin{array}{l}\text { 24. Viver com um transtorno mental te tornou um } \\
\text { forte sobrevivente. }\end{array}$ & 1 & 2 & 3 & 4 \\
\hline $\begin{array}{l}\text { 25. Ninguém se interessaria em se aproximar de você } \\
\text { porque você tem um transtorno mental. }\end{array}$ & 1 & 2 & 3 & 4 \\
\hline $\begin{array}{l}\text { 26. Geralmente, você é capaz de viver uma vida } \\
\text { como você quer. }\end{array}$ & 1 & 2 & 3 & 4 \\
\hline $\begin{array}{l}\text { 27. Você pode ter uma vida boa, plena, apesar de seu } \\
\text { transtorno mental. }\end{array}$ & 1 & 2 & 3 & 4 \\
\hline $\begin{array}{l}\text { 28. Os outros pensam que você não pode alcançar } \\
\text { muito na vida por você ter um transtorno mental. }\end{array}$ & 1 & 2 & 3 & 4 \\
\hline $\begin{array}{l}\text { 29. As imagens sobre as pessoas com transtomo } \\
\text { mental se aplicam a você. }\end{array}$ & 1 & 2 & 3 & 4 \\
\hline
\end{tabular}


Anexo 2 - Autorização para o uso da Escala de Estigma Internalizado - ISMI-BR

Em 4 de março de 2015 14:45, telmo ronzani <m_ronzani@gmail.com> escreveu:

Prezada Kelly.

Ficamos satisfeitos em saber de seu interesse no uso da ISMI-BR. A validação da versão para transtorno mental está em submissão para revista e estamos aguardanda a aprovação. A escala é de uso livre e aberto. Pedimos somente que cite a fonte da validação em sua pesquisa. Estou copiando o email para as demais autoras para the mandar o que temos publicado sobre a escala.

Qualquer coisa, estamos à disposição.

Abraços,

Em 3 de março de 2015 23:05, <kelly. giacchera@gmail.com> escreveu:

Prezado Prof. Telmo Mota Ronzani

Sou Professora Doutora da Escola de Enfermagem de Ribeirão Preto da Universidade de São Paulo (EERP-USP)

e pretendo iniciar uma investigação sobre estigma entre pessoas com transtorno mental.

Tomei conhecimento sobre a tradução e validação da ESCALA DE ESTIGMA INTERNALIZADO PARA

TRANSTORNO MENTAL - ISMI-BRE por meio de uma dissertação de mestrado orientada pelo senhor

Por meio deste e-mail, venho solicitar de Vossa Senhoria a autorização para utilização do instrumento e verificar

quais os procedimentos necessários para sua utilização

Desde já, agradeço pela atenção.

Atenciosamente,

Kelly G Giacchero Vedana

Enviada do meu iPad

Prof. Dr. Telmo M. Ronzani 
Anexo 3 - Escala de Medida de Adesão ao Tratamento - MAT

Medida de Adesão aos Tratamentos (MAT)

\begin{tabular}{|c|c|c|c|c|c|}
\hline \multicolumn{6}{|c|}{ 1. Alguma vez se esqueceu de tomar os medicamentos para a sua doença? } \\
\hline Sempre & quase sempre & com frequência & por vezes & Raramente & Nunca \\
\hline 1 & 2 & 3 & 4 & 5 & 6 \\
\hline \multicolumn{6}{|c|}{ 2. Alguma vez foi descuidado com as horas da toma dos medicamentos para a sua doença? } \\
\hline Sempre & quase sempre & com frequência & por vezes & Raramente & Nunca \\
\hline 1 & 2 & 3 & 4 & 5 & 6 \\
\hline \multicolumn{6}{|c|}{ 3. Alguma vez deixou de tomar os medicamentos para a sua doença por se ter sentido melhor? } \\
\hline Sempre & quase sempre & com frequência & por vezes & Raramente & Nunca \\
\hline 1 & 2 & 3 & 4 & 5 & 6 \\
\hline \multicolumn{6}{|c|}{$\begin{array}{l}\text { 4. Alguma vez deixou de tomar os medicamentos para a sua doença, por sua iniciativa, após se ter sentido } \\
\text { pior? }\end{array}$} \\
\hline Sempre & quase sempre & com frequência & por vezes & Raramente & Nunca \\
\hline 1 & 2 & 3 & 4 & 5 & 6 \\
\hline \multicolumn{6}{|c|}{$\begin{array}{l}\text { 5. Alguma vez tomou mais um ou vários comprimidos para a sua doença, por sua iniciativa, após se ter senti- } \\
\text { do pior? }\end{array}$} \\
\hline Sempre & quase sempre & com frequência & por vezes & Raramente & Nunca \\
\hline 1 & 2 & 3 & 4 & 5 & 6 \\
\hline \multicolumn{6}{|c|}{ 6. Alguma vez interrompeu a terapêutica para a sua doença por ter deixado acabar os medicamentos? } \\
\hline Sempre & quase sempre & com frequência & por vezes & Raramente & Nunca \\
\hline 1 & 2 & 3 & 4 & 5 & 6 \\
\hline \multicolumn{6}{|c|}{$\begin{array}{l}\text { 7. Alguma vez deixou de tomar os medicamentos para a sua doença por alguma outra razão que não seja a } \\
\text { indicação do médico? }\end{array}$} \\
\hline Sempre & quase sempre & com frequência & por vezes & Raramente & Nunca \\
\hline 1 & 2 & 3 & 4 & 5 & 6 \\
\hline
\end{tabular}


Anexo 4 - Escala de Avaliação Psiquiátrica Breve Ancorada (BPRS-a) modificada

\begin{tabular}{|c|c|}
\hline Item & Definições \\
\hline $\begin{array}{l}01 \text { - Preocupações somáticas } \\
\text { Este item compreende a hipocondria. Os graus I e } 2 \\
\text { da escala referem-se à hipocondria não delirante e } \\
\text { os graus } 3 \text { e } 4 \text { à hipocondria delirante. }\end{array}$ & $\begin{array}{l}\text { 0. Atenção normal com a saúde física. } \\
\text { 1. Grau mínimo ou duvidoso de preocupação excessiva com a saúde } \\
\text { física. } \\
\text { 2. O paciente expressa idéias de ter uma doença orgânica (p.ex., câncer } \\
\text { ou doença cardíaca), mas sem interpretações delirantes. } \\
\text { 3. As queixas são bizarras (p.ex., de estar apodrecendo por dentro), mas } \\
\text { pode-se conseguir que o paciente, por breves períodos, admita que este } \\
\text { não é o seu caso. } \\
\text { 4. Está convencido, p.ex., de que seus órgãos estão podres ou } \\
\text { desaparecendo, ou de que vermes estão devorando seu cérebro. Nem } \\
\text { por breves períodos se pode fazê-lo admitir que este não é o seu caso. }\end{array}$ \\
\hline $\begin{array}{l}\mathbf{0 2} \text { - Ansiedade psíquica } \\
\text { Este item compreende tensão, irritabilidade, } \\
\text { preocupação, insegurança, medo e apreensão, que se } \\
\text { aproximam ao pavor subjugante. Frequentemente } \\
\text { pode ser difícil distinguir entre a vivência de } \\
\text { ansiedade do paciente (os fenômenos de ansiedade } \\
\text { "psíquica" ou "central") e as manifestaçôes } \\
\text { fisiológicas de ansiedade (periférica) que podem ser } \\
\text { observadas, como tremor das mãos e sudorese. Muito } \\
\text { importante, neste item, é o relato do paciente de } \\
\text { preocupação, insegurança, incerteza, vivências de } \\
\text { pavor, ou seja, de ansiedade psíquica ("central") }\end{array}$ & $\begin{array}{l}\text { 0. O paciente não se encontra nem mais nem menos inseguro ou irritável } \\
\text { do que o habitual. } \\
\text { 1. É duvidoso se o paciente está mais inseguro ou irritável do que o } \\
\text { habitual. } \\
\text { 2. O paciente expressa mais claramente estar em um estado de ansiedade, } \\
\text { apreensão ou irritabilidade, que pode achar difícil de controlar. Isso } \\
\text { ocorre sem influir no dia-a-dia do paciente, porque a preocupação } \\
\text { ainda diz respeito a questões pouco importantes. } \\
\text { 3. A ansiedade ou insegurança é, às vezes, mais difícil de controlar } \\
\text { porque a preocupação diz respeito a perdas ou danos importantes, que } \\
\text { podem ocorrer no futuro. P.ex., a ansiedade pode ser vivenciada como } \\
\text { pânico, ou seja, como pavor subjugante. Ocasionalmente esta } \\
\text { ansiedade já interferiu no dia-a-dia do paciente. } \\
\text { 4. A sensação de pavor está tão frequentemente presente que interfere } \\
\text { acentuadamente no dia-a-dia do paciente. }\end{array}$ \\
\hline $\begin{array}{l}\mathbf{0 3} \text { - Retraimento emocional } \\
\text { Este item compreende a vivência introspectiva de } \\
\text { contato emocional com o paciente durante a } \\
\text { entrevista. Ele se contrapõe ao item } 16 \text { (afeto } \\
\text { embotado ou inapropriado), que compreende o grau } \\
\text { de contato emocional com outras pessoas, avaliado } \\
\text { retrospectivamente durante os três dias precedentes. }\end{array}$ & $\begin{array}{l}\text { 0. Contato emocional normal. } \\
\text { 1. Alguma (ou duvidosa) distância emocional } \\
\text { 2. Reações emocionais reduzidas, como por exemplo, contato visual } \\
\text { duvidoso. } \\
\text { 3. Reações emocionais mais limitadas, como por exemplo, contato visual } \\
\text { ocasionalmente inadequado. } \\
\text { 4. Quando o contato emocional está fortemente reduzido ou quase } \\
\text { ausente, como por exemplo, quando evita o contato visual. }\end{array}$ \\
\hline $\begin{array}{l}\text { 04 - Desorganização conceitual } \\
\text { (incoerência) } \\
\text { Este item compreende os distúrbios do processo de } \\
\text { pensamento, desde certa imprecisão na expressão } \\
\text { verbal até produções verbais completamente } \\
\text { desorganizadas. }\end{array}$ & $\begin{array}{l}\text { 0. Ausência de desorganização conceitual } \\
\text { 1. O pensamento é caracterizado por uma certa imprecisão, mas a fala } \\
\text { não é gramaticalmente inusal. } \\
\text { 2. Distúrbio moderado do pensamento. As palavras podem estar ligadas } \\
\text { através de uma forma gramaticalmente inusal e particular ("pars pro } \\
\text { toto") e a informação que comunica parece "vazia". } \\
\text { 3. Acentuada desorganização conceitual. Ocasionalmente torna-se difícil } \\
\text { entender o paciente, podendo surgir neologismos ou bloqueio } \\
\text { 4. Desorganização conceitual extremamente grave. Apenas fragmentos } \\
\text { da fala são compreensíveis. }\end{array}$ \\
\hline $\begin{array}{l}\text { 05 - Auto-depreciação e sentimentos de culpa } \\
\text { Este item compreende a diminuição da auto-estima, } \\
\text { com sentimentos de culpa. }\end{array}$ & $\begin{array}{l}\text { 0. Ausência de auto-depreciação e sentimentos de culpa. } \\
\text { 1. É duvidoso se sentimentos de culpa estão presentes, pois o paciente } \\
\text { está apenas preocupado com o fato de que ele, durante a doença atual, } \\
\text { seja um peso para a familia ou colegas, devido à sua reduzida } \\
\text { capacidade de trabalho. } \\
\text { 2. Auto-depreciação ou sentimentos de culpa estão mais claramente } \\
\text { presentes, pois o paciente está preocupado com incidentes do passado, } \\
\text { anteriores ao episódio atual. Por exemplo, o paciente acusa-se de } \\
\text { pequenas omissões ou falhas, de não ter cumprido com o seu dever ou } \\
\text { de haver prejudicado outras pessoas. } \\
\text { 3. O paciente experimenta sentimentos de culpa mais graves. Ele pode } \\
\text { afirmar que sente que o seu sofrimento atual é algum tipo de punição. } \\
\text { Assinale } 3 \text { desde que o paciente possa perceber intelectualmente que } \\
\text { sua opinião é infundada. } \\
\text { 4. Os sentimentos de culpa são firmemente mantidos e resistem a } \\
\text { qualquer argumentação, de modo que se converteram em idéias } \\
\text { paranóides. }\end{array}$ \\
\hline $\begin{array}{l}\text { 06- Ansiedade } \\
\text { Este item compreende os concomitantes fisiológicos } \\
\text { da ansiedade, que se manifestaram durante a } \\
\text { entrevista. Todos os estados subjetivos de ansiedade } \\
\text { devem ser assinalados no item } 2 \text {, e não aqui. }\end{array}$ & $\begin{array}{l}\text { 0. Quando o paciente não está nem mais nem menos propenso que o } \\
\text { habitual a experimentar concomitantes somáticos de estados de } \\
\text { ansiedade. } \\
\text { 1. Quando o paciente ocasionalmente apresenta leves manifestações, } \\
\text { como sintomas abdominais, sudorese ou tremores. Entretanto, a } \\
\text { descrição desses sintomas é vaga e questionável. } \\
\text { 2. Quando o paciente ocasionalmente apresenta sintomas abdominais, } \\
\text { sudorese, tremores, etc. Os sinais e sintomas são claramente descritos, } \\
\text { porém não são acentuados e nem incapacitantes. } \\
\text { 3. Os concomitantes emocionais dos estados subjetivos de ansiedade são } \\
\text { acentuados e, às vezes, muito preocupantes. } \\
\text { 4. Os concomitantes fisiológicos dos estados subjetivos de ansiedade são } \\
\text { numerosos, persistentes e frequientemente incapacitantes. }\end{array}$ \\
\hline $\begin{array}{l}\text { 07 - Distúrbios motores específicos } \\
\text { Este item compreende os graus variáveis de } \\
\text { comportamento motor bizarro, que vai desde certa } \\
\text { excentricidade na postura até a agitação catatônica } \\
\text { severa. }\end{array}$ & $\begin{array}{l}\text { 0. Ausente. } \\
\text { 1. Leve ou de presença duvidosa durante a entrevista. } \\
\text { 2. Moderada. Presente durante a maior parte da entrevista. } \\
\text { 3. Severa. Anormalidades motoras contínuas. Podem ser interrompidas. } \\
\text { 4. Extremamente severa. Anormalidades motoras persistentes e } \\
\text { incontroláveis. Entrevista difícil. }\end{array}$ \\
\hline
\end{tabular}




\begin{tabular}{|c|c|}
\hline $\begin{array}{l}\text { o8 - Auto-estima exagerada } \\
\text { Este item compreende graus variáveis de exagero da } \\
\text { auto-estima, variando desde uma acentuada auto- } \\
\text { confiança ou presunção, até os delírios de grandeza } \\
\text { grotescos. }\end{array}$ & $\begin{array}{l}\text { 0. Auto-estima normal. } \\
\text { 1. Auto-estima aumentada levemente ou de maneira duvidosa, como por } \\
\text { exemplo: ocasionalmente superestima suas próprias capacidades } \\
\text { habituais. } \\
\text { 2. Auto-estima moderadamente aumentada. Por exemplo, superestima } \\
\text { mais constantemente suas próprias capacidades habituais ou insinua } \\
\text { possuir capacidades incomuns. } \\
\text { 3. Idéias acentuadamente irreais, como por exemplo, de que tem } \\
\text { habilidades, poderes ou conhecimentos (científicos, religiosos, etc.) } \\
\text { extraordinários, mas pode, por breves períodos ser corrigido. } \\
\text { 4. Idéias de grandeza que não podem ser corrigidas. }\end{array}$ \\
\hline $\begin{array}{l}\text { 09 - Humor Deprimido } \\
\text { Este item compreende tanto a comunicação verbal } \\
\text { como a não verbal de tristeza, depressão, desânimo, } \\
\text { desamparo e desesperança. }\end{array}$ & $\begin{array}{l}\text { 0. Humor neutro. } \\
\text { 1. O paciente indica vagamente que está mais desanimado e deprimido } \\
\text { que o habitual. } \\
\text { 2. Quando o paciente está mais claramente preocupado com vivências } \\
\text { desagradáveis, embora ainda não esteja se sentindo desamparado ou } \\
\text { desesperançado. } \\
\text { 3. O paciente exibe sinais não verbais claros de depressão e/ou às vezes } \\
\text { sente-se dominado pelo desamparo ou desesperança. } \\
\text { 4. As observações do paciente sobre desânimo e desamparo, ou as suas } \\
\text { manifestaçôes não verbais, dominam a entrevista, não sendo possível } \\
\text { afastá-lo desta temática. }\end{array}$ \\
\hline $\begin{array}{l}10 \text { - Hostilidade } \\
\text { Este item compreende o relato verbal do paciente de } \\
\text { sentimentos ou açôes hostis em relação a outras } \\
\text { pessoas fora da entrevista. Trata-se de um } \\
\text { julgamento retrospectivo dos três dias precedentes. } \\
\text { Diferenciar do item } 14 \text { (Falta de cooperação), que } \\
\text { corresponde ao contato formal durante a entrevista. }\end{array}$ & $\begin{array}{l}\text { 0. Ausência de sinais de impaciência, irritabilidade, crítica ou hostilidade. } \\
\text { 1. Esteve um pouco impaciente ou irritável, mas o controle foi mantido. } \\
\text { 2. Esteve moderadamente impaciente ou irritável, mas tolerou as } \\
\text { provocações. } \\
\text { 3. Esteve verbalmente hostil, faz ameaças e quase chegou a ser } \\
\text { fisicamente destrutivo, mas ainda pôde ser acalmado. } \\
\text { 4. Extremamente hostil, com violência física manifesta. Fisicamente } \\
\text { destrutivo. }\end{array}$ \\
\hline $\begin{array}{l}11 \text { - Desconfiança } \\
\text { Este item compreende a desconfiança, a suspeita ou } \\
\text { as interpretaçōes distorcidas, variando desde uma } \\
\text { acentuada falta de confiança nos outros até os } \\
\text { delírios de perseguição floridos. }\end{array}$ & $\begin{array}{l}\text { 0. Ausente. } \\
\text { 1. Vagas idéias de referência. Tende a suspeitar que as outras pessoas } \\
\text { estão falando ou rindo de si. Sente que "alguma coisa está ocorrendo". } \\
\text { Responde ao reasseguramento; portanto, fica duvidoso se existem } \\
\text { idéias de referência ou delírios. } \\
\text { 2. Idéias de referência com delírios vagos, não sistematizados, de } \\
\text { perseguição. "Alguém pode ter más intenções". Isto é insinuado pela } \\
\text { televisão ou pelos jornais. Ainda se trata de uma vivência do tipo } \\
\text { "como se". } \\
\text { 3. Delírios com alguma sistematização. Reasseguramento difícil. } \\
\text { 4. Delírios paranóides sistematizados, floridos, de perseguição. Correção } \\
\text { impossível. }\end{array}$ \\
\hline
\end{tabular}




\section{2 - Alucinações} os estímulos externos correspondentes. As vivêncio alucinatórias devem ter ocorrido nos três últimos dias e, com exceção das alucinações hipnagógicas, não devem ter ocorrido durante os estados de turvação da consciência (delirium).

\section{3 - Retardo psicomotor} atividade psicomotora, que inclui a velocidade de associações e a capacidade para verbalizar os pensamentos. Os sintomas do retardo motor dizen respeito à postura, aos gestos e à expressão facial.
Este item compreende as percepções sensoriais sem

Este item compreende a redução do nivel de

\section{Ausente.}

1. Em grau leve ou de presença duvidosa. Vivências alucinatórias hipnagógicas ou vivências alucinatórias elementares isoladas (ouvir sons, ver luzes).

2. Alucinações ocasionais, mas plenamente desenvolvidas (ouvir vozes, ver formas), que não afetam o comportamento.

3. Alucinações ocasionais que influenciam o comportamento.

4. Mais ou menos constantemente absorto em vivências alucinatórias.

0. Atividade verbal normal, atividade motora normal, com expressão facial adequada.

1. Velocidade de conversação duvidosa ou levemente reduzida e expressão facial duvidosa ou levemente diminuída.

2. Velocidade de conversação claramente reduzida, com pausas; gestos reduzidos e movimentação lenta.

3. A entrevista é claramente prolongada devido às longas latências e respostas curtas; todos os movimentos estão muito lentos.

4. A entrevista não pode ser completada; o retardo se aproxima de (e inclui) estupor.

\section{4 - Falta de cooperação}

Este item compreende a atitude e as respostas do paciente ao entrevistador e à situação da entrevista. Difere do item 10 (hostilidade) por que este compreende a falta de cooperação com outras pessoas durante os 3 dias precedentes.

\section{Atitude cooperativa natural.}

1. Excessivamente formal e reservado na situação de entrevista.

Responde um pouco resumidamente.

2. Resistência moderada. Responde evasivamente ou opõe-se a determinadas perguntas. Atitude acentuadamente hostil para com o entrevistador.

3. Resistência pronunciada. Responde inapropriadamente ou recusa-se a responder. Atitude abertamente hostil. Entrevista completa não é possível.

4. Entrevista impossível. O paciente recusa-se a permanecer na situação de entrevista.

15 - Conteúdo do pensamento incomum

Este item diz respeito ao conteúdo da verbalização do paciente e não à organização a linguagem, que é assinalada no item 4 (desorganização conceitual). $O$ item refere-se às qualidades incomuns até os vários niveis de idéias delirantes. Observe que os "delirios de grandeza" são assinalados no item 8 (auto-estima exagerada), que os "delirios de culpa" são assinalados no item 5 (sentimentos de culpa), e que os "delirios de perseguição" são assinalados no item 11 (desconfiança). Os delírios que apresentam interesse especial aqui são os delírios de controle. influência ou despersonalização, ciúme mórbido, delírios sexuais, delírios religiosos ou expansivos. Assinale apenas o grau de raridade do conteúdo expresso do pensamento, a importância que apresenta para o paciente ou a influência que exerce sobre o seu comportamento.

\section{Ausente.}

1. Grau leve ou presença duvidosa (por exemplo, idéias supervalorizadas).

2. Grau moderado (por exemplo, idéias com alguma qualidade delirante, mas ainda se constituindo em uma vivência do tipo "como se").

3. Os delírios delimitam a maior parte do conteúdo do pensamento e ocasionalmente influenciam o comportamento.

4. Delírios subjugantes delimitam o conteúdo do pensamento e o comportamento. 
16 - Afeto embotado ou inapropriado Este item compreende a diminuição da capacidade ou da motivação para sentir ou expressar as emoçõe emoções, manifestadas verbalmente e não verbalmente, são perceptivelmente inapropriadas à situação ou ao conteúdo do pensamento. Este item compreende, assim, o retraimento emocional relativo às outras pessoas, durante os três dias precedentes. Discriminar do item 3 (retraimento emocional), que diz respeito à vivência introspectiva do contato emocional durante a entrevista.

17 - Agitação psicomotor

Este item compreende o aumento no nível da atividade psicomotora. normais, como a tristeza, alegria e raiva. As

0. Reações e envolvimento emocionais apropriados.

1. Reações emocionais escassas ou questionavelmente inapropriadas. Por exemplo, menor desejo ou capacidade de estar em companhia de pessoas que conhece há mais ou menos tempo.

2. Afeto perceptivelmente embotado. Não apresenta necessidade ou capacidade de estabelecer contato mais íntimo com pessoas não pertencentes ao seu círculo familiar (companheiros de trabalho, outros pacientes, equipe terapêutica).

3. Emocionalmente indiferente e apático, mesmo em relação aos amigos íntimos e à família.

4. Emocionalmente ausente, ou então os afetos manifestados são grosseiramente inapropriados, sem qualquer motivação para o contato humano.

0. Atividade motora normal. Expressão facial adequada e atividade verbal normal.

1. Atividade motora duvidosa ou levemente aumentada; por exemplo, expressão facial vívida ou certa loquacidade.

2. Atividade motora moderadamente aumentada; por exemplo, gestos vívidos ou grande loquacidade ou fala em voz alta e rapidamente.

3. Atividade motora claramente excessiva, movimentando-se durante a maior parte do tempo. Levanta-se uma ou várias vezes durante a entrevista. Fuga de idéias. Dificuldade para compreendê-lo.

4. Constante e incansavelmente ativo. Fala desintegrada. Comunicação significativa impossível.

18 - Desorientação e confusão

Este item compreende os graus de turvação da consciência, com redução ou perda de orientação no tempo elou quanto a dados pessoais.
0. O paciente está completamente orientado no tempo, no espaço, e quanto aos dados pessoais

1. O paciente ocasionalmente tem algumas dificuldades, mas pode corrigir espontaneamente sua afirmação sobre a orientação no tempo, e/ou no espaço, e/ou quanto aos dados pessoais.

2. O paciente apresenta falhas que não são corrigidas espontaneamente. Por exemplo, não sabe o dia da semana ou do mês, embora saiba o mês e o ano corretamente, e/ou tem dificuldades espaciais, embora esteja orientado na enfermaria (ou em sua casa), e/ou tem dificuldades para recordar nomes, embora ainda saiba seu próprio nome.

3. O paciente está acentuadamente desorientado. Por exemplo, não sabe o mês e o ano corretamente, embora ainda se localize quanto a períodos significati vos do ano (carnaval, festas juninas, natal)*, e/ou tem dificuldades para localizar o banheiro ou a sua cama sem auxílio, e/ou lembra seu próprio nome apenas através de alguma ajuda.

4. Está completamente desorientado no tempo e/ou no espaço, e/ou quanto aos dados pessoais.

* Adaptação à realidade brasileira. No original, "estações do ano" 


\section{Anexo 5 - Guia de aplicação da Escala de Avaliação Psiquiátrica Breve Ancorada (BPRS-a) modificada}

Structured Interview Guide for Brief Psychiatric Rating Scale (SIG-BPRS)

Observação: $O$ entrevistador deve julgar as condições do paciente no momento da entrevista. Os itens 2 (ansiedade psíquica), 10 (hostilidade), 11 (desconfiança), 12 (alucinações), 15 (conteúdo incomum do pensamento) e 16 (afeto embotado ou inapropriado) devem ser avaliados tomando-se por base as condiçōes do paciente nos últimos três dias.

\section{Contato Inicial}

\begin{tabular}{|c|l|}
\hline ITEM DO BPRS & \multicolumn{1}{|c|}{ PERGUNTAS-GUIA } \\
\hline & Entrevista inicial \\
\hline Orientação & $\begin{array}{l}\text { Qual o seu nome completo? E sua idade? Onde você mora? Com quem você mora? } \\
\text { Está trabalhando atualmente? (Já trabalhou anteriormente? Em quê?) }\end{array}$ \\
\hline $\begin{array}{c}\text { Preocupação } \\
\text { Somática }\end{array}$ & $\begin{array}{l}\text { Como costuma ser sua saúde física (do corpo)? Como esteve a sua saúde no último } \\
\text { ano? Você está preocupado com algum problema de saúde agora? }\end{array}$ \\
\hline Orientação & $\begin{array}{l}\text { Quanto tempo faz que você está aqui? Conte-me por que motivo você foi internado. } \\
\text { Quando isso começou? O que aconteceu depois? Você pode me dizer que dia é } \\
\text { hoje? (semana, mês, ano). }\end{array}$ \\
\hline Triagem & Reentrevista \\
\hline Orientação & $\begin{array}{l}\text { Como tem passado desde a nossa última conversa? O que o tem incomodado mais } \\
\text { nos últimos dias? (Além disso, o que mais incomoda você?) }\end{array}$ \\
\hline Preocupação pode me dizer que dia é hoje? (semana, mês, ano). Você pode me dizer o que \\
tinha ontem no jantar?
\end{tabular}

2. Entrevista

\begin{tabular}{|c|c|}
\hline ITEM DO BPRS & PERGUNTAS -GUIA \\
\hline Orientação & $\begin{array}{l}\text { Você tem conseguido se concentrar? Como está sua memória? } \\
\text { (Caso necessário, faça exame específico) }\end{array}$ \\
\hline $\begin{array}{l}\text { Ansiedade } \\
\text { Psiquica }\end{array}$ & $\begin{array}{l}\text { Você está preocupado com alguma coisa? Você tem se sentido tenso ou ansioso a } \\
\text { maior parte do tempo? (Quando se sente assim, você consegue saber por quê? De } \\
\text { que forma as suas ansiedades ou preocupaçōes afetam o seu dia-a-dia? Existe algo } \\
\text { que ajuda a melhorar esta sensação?) }\end{array}$ \\
\hline $\begin{array}{l}\text { Sentimentos de } \\
\text { Culpa }\end{array}$ & $\begin{array}{l}\text { Nos últimos dias você tem se sentido um peso para sua fam ilia ou colegas? Você } \\
\text { tem se sentido culpado por alguma coisa feita no passado? Você acha que o que } \\
\text { você está passando agora é um tipo de castigo? (Por que você acha isso?) }\end{array}$ \\
\hline ITEM DO BPRS & PERGUNT AS -GUIA \\
\hline Humor Deprimido & $\begin{array}{l}\text { Como tem estado o seu humor (alegre, triste, irritável)? Você acredita que pode } \\
\text { melhorar? (Como este sentimento tem afetado o seu dia-a-dia?) }\end{array}$ \\
\hline Desconfiança $a^{(*)}$ & $\begin{array}{l}\text { Você tem tido a impressão de que as outras pessoas estão falando ou rindo de } \\
\text { vocêe? (De que forma você percebe isso?) Você tem achado que tem alguém com } \\
\text { más intenções contra você ou se esforçando para lhe causar problemas? (Quem? } \\
\text { Por quê? Como você sabe disso?) }\end{array}$ \\
\hline $\begin{array}{l}\text { Auto-Estima } \\
\text { Exagerada }^{(*)} \\
\text { (Hostilidade) }\end{array}$ & $\begin{array}{l}\text { Nos últimos dias você tem se sentido com algum talento ou habilidade que a maioria } \\
\text { das pessoas não tem? (Como você sabe disso?) Você acha que as pessoas têm } \\
\text { tido inveja de você?? Você tem acreditado que tenha alguma coisa importante para } \\
\text { fazer no mundo? Nos últimos dias você tem estado impaciente ou irritável com as } \\
\text { outras pessoas? (Conseguiu manter o controle? Tolerou as provocações? Chegou a } \\
\text { agredir alguém ou a quebrar objetos?) }\end{array}$ \\
\hline $\begin{array}{l}\text { Conteúdo } \\
\text { Incomum do } \\
\text { Pensamento } \\
\text { (Preocupação } \\
\text { Somática) }\end{array}$ & $\begin{array}{l}\text { Você tem acreditado que alguém ou alguma coisa fora de você esteja controlando } \\
\text { seus pensamentos ou suas açōes contra sua vontade? Você tem a impressão de } \\
\text { que o rádio ou a televisão mandam mensagens para você? Você sente que alguma } \\
\text { coisa incomum esteja acontecendo ou está para acontecer? Você sente que tem } \\
\text { alguma coisa incomum acontecendo no seu corpo ou cabeça? }\end{array}$ \\
\hline Alucinaçōes ${ }^{(*)}$ & $\begin{array}{l}\text { Você tem tido experiências incomuns, que a maioria das pessoas não tem? Você } \\
\text { tem escutado coisas que as outras pessoas não podem ouvir? (Você estava } \\
\text { acordado neste momento? O que você ouvia [barulhos, cochichos, vozes } \\
\text { conversando com você ou conversando entre si]? Com que freqüência? Interferem } \\
\text { no seu dia-a-dia?) } \\
\text { Você tem visto coisas que as outras pessoas não podem ver? (Você estava } \\
\text { acordado neste momento? O que você via [luzes, formas, imagens]? Com que } \\
\text { freqüência? Interferem no seu dia-a-dia?) }\end{array}$ \\
\hline
\end{tabular}

\section{Encerramento}

Estas eram as perguntas que eu precisava fazer. Tem alguma coisa que o senhor(a) acha importante dizer, que eu não perguntei ou alguma coisa que gostaria de perguntar? 
Anexo 6 - Autorização para o uso da Escala de Avaliação Psiquiátrica Breve Ancorada (BPRS-a) modificada

Dayane,
Fique a vontade para utilizar a escala.
Envio o artigo solicitado, porém alerto que essa estrutura fatorial foi modificada por um trabalho mais recente de 2002, que também estou enviando.
Att.,
Zuardi


Anexo 7 - Escala de Esperança de Herth (EEH)

\section{ESCALA DE ESPERANÇA DE HERTH (EEH)}

Várias afirmaç̃es estão abaixo enumeradas. Leia cada afirmação e coloque um [X] na coluna que descreve o quanto você concorda com esta afirmação neste momento.

\begin{tabular}{|l|l|l|l|l|}
\hline & $\begin{array}{l}\text { Discordo } \\
\text { completamente }\end{array}$ & Discordo & Concordo & $\begin{array}{c}\text { Concordo } \\
\text { completamente }\end{array}$ \\
\hline 1. Eu estou otimista quanto à vida. & & & & \\
\hline 2. Eu tenho planos a curto e longo prazos. & & & & \\
\hline 3. Eu me sinto muito sozinho(a). & & & & \\
\hline $\begin{array}{l}\text { 4. Eu consigo ver possibilidades em meio às } \\
\text { dificuldades. }\end{array}$ & & & & \\
\hline 5. Eu tenho uma fé que me conforta. & & & & \\
\hline 6. Eu tenho medo do meu futuro. & & & & \\
\hline $\begin{array}{l}\text { 7. Eu posso me lembrar de tempos felizes e } \\
\text { prazerosos. }\end{array}$ & & & & \\
\hline 8. Eu me sinto muito forte. & & & & \\
\hline $\begin{array}{l}\text { 9. Eu me sinto capaz de dar e receber } \\
\text { afeto/amor. }\end{array}$ & & & & \\
\hline 10. Eu sei onde eu quero ir. & & & & \\
\hline 11. Eu acredito no valor de cada dia. & & & & \\
\hline $\begin{array}{l}\text { 12. Eu sinto que minha vida tem valor e } \\
\text { utilidade. }\end{array}$ & & & & \\
\hline
\end{tabular}


Anexo 8 - Autorização para o uso da Escala de Esperança de Herth (EEH)

Research Development

-...-.- Mensagem encaminhada -.......-

De: Alessandra Cristina Sartore Balsanelli <alessandrasartore@hotmail.com>

Data: 5 de março de 2015 14:39

Assunto: RE: Escala de Esperança de Herth - Instrumento

Para: "kelly.giacchero@gmail.com" <kelly.giacchero@gmail.com>

Cc: Prof Sônia USP < sogrossi@usp. brr $>$

Prezada Professora Kelly

A Escala de Esperança de Herth está disponibilizada para a língua Portuguesa e pode ser utilizada em indivíduos adultos, em situações clínicas.

Temos estudos nacionais com pacientes diabéticos e oncológicos (validação) e mulheres com HIV. Certamente o estudo em pacientes com transtorno mental trará grandes contribuições.

A Escala é de fácil e rápida aplicação. Está disponibilizada no artigo, bem como os valores dos escores das frases Relembro somente que as frases de número 3 (três) e 6 (seis) tem escores invertidos.

Coloco-me à disposição para outros esclarecimentos.

Att 